\title{
Relativistic Effects on a Metal-Metal Bond: Osmium Corrole Dimers
}

\author{
Abraham B. Alemayehu, ${ }^{\mathrm{a}}$ Laura J. M Cormick, $^{\mathrm{c}}{ }^{\mathrm{b}}$ Hugo Vazquez-Lima, ${ }^{\mathrm{a}}$ and Abhik Ghosh*,a \\ ${ }^{a}$ Department of Chemistry, UiT - The Arctic University of Norway, N-9037 Tromsø, Norway; \\ Email: abhik.ghosh@uit.no; Telephone: +47 45476145 \\ ${ }^{\mathrm{b}}$ Advanced Light Source, Lawrence Berkeley National Laboratory, \\ Berkeley, CA 94720-8229, USA
}

\section{For Table of Contents only}

The first osmium corrole dimers have been synthesized, affording an experimentally calibrated analysis of relativistic effects on a metal-metal bond.

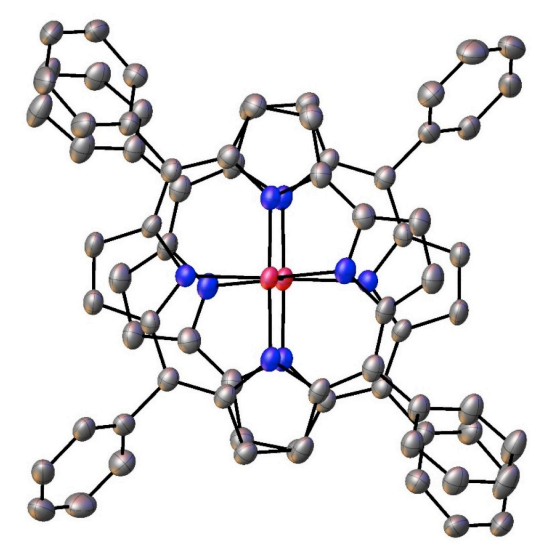


Abstract. A series of metal-metal bonded osmium corrole dimers, $\{\mathrm{Os}[\mathrm{T} p \mathrm{XPC}]\}_{2}$, were synthesized in reasonably good yields (36-45\%) via the interaction of the corresponding freebase meso-tris $\left(p\right.$-X-phenyl)corroles $\left(\mathrm{H}_{3}[\mathrm{~T} p \mathrm{XPC}], \mathrm{X}=\mathrm{CF}_{3}, \mathrm{H}, \mathrm{CH}_{3}\right.$, and $\left.\mathrm{OCH}_{3}\right), \mathrm{Os}_{3}(\mathrm{CO})_{12}$, and potassium carbonate in 1,2,4-trichlorobenzene under an inert atmosphere at $180^{\circ} \mathrm{C}$ over several hours. The complexes are only the second class of Os corroles reported to date (the first being $\mathrm{Os}^{\mathrm{VI}} \mathrm{N}$ corroles) and also the second class of metal-metal bonded metallocorrole dimers (the other being Ru corrole dimers). Comparison of the X-ray structures, redox potentials, and optical spectra of analogous Ru and Os corrole dimers, along with pertinent scalar-relativistic DFT calculations, has provided an experimentally calibrated account of relativistic effects in these complexes. Three of the Os corrole dimers $\left(\mathrm{X}=\mathrm{CF}_{3}, \mathrm{H}\right.$, and $\left.\mathrm{OCH}_{3}\right)$ were analyzed with singlecrystal X-ray diffraction analysis, revealing inversion-related corrole rings with eclipsed Os-N bonds and Os-Os distances of $\sim 2.24 \AA$ that are $\sim 0.06 \AA$ longer than the Ru-Ru distances in the analogous Ru corrole dimers. Interestingly, a comparison of scalar-relativistic and nonrelativistic DFT calculations indicates that this difference in metal-metal bond distance does not, in fact, reflect a differential relativistic effect. For a given corrole ligand, the $\mathrm{Ru}$ and Os corrole dimers exhibit nearly identical oxidation potentials, but dramatically different reduction potentials, with the Os values $\sim 0.5 \mathrm{~V}$ lower relative to $\mathrm{Ru}$, suggesting that whereas oxidation occurs in a ligandcentered manner, reduction is substantially metal-centered, which indeed was confirmed by scalar-relativistic calculations. The calculations further indicate that approximately a third of the $\sim 0.5 \mathrm{~V}$ difference in reduction potentials can be ascribed to relativity. The somewhat muted value of this relativistic effect appears to be related to the finding that reduction of an Os corrole dimer is not exclusively metal-based, but that a significant amount of spin density is delocalized over to the corrole ligand; in contrast, reduction of an Ru corrole dimer occurs exclusively on the $\mathrm{Ru}-\mathrm{Ru}$ linkage. For isoelectronic complexes, the $\mathrm{Ru}$ and Os corrole dimers exhibit substantially different UV-vis spectra. A key difference is a strong near-UV feature of the Os series, which in energy terms is blue-shifted by $\sim 0.55 \mathrm{~V}$ relative to the analogous feature of the Ru series. TDDFT calculations suggest that this difference may be related to higher-energy Os(5d)-based LUMOs in the Os case relative to analogous MOs for Ru. 
Introduction. It is a matter of common knowledge that second- and third-row transition metals are chemically much more similar to one another than to their first-row counterparts. ${ }^{1}$ This similarity is thought to reflect the larger size of the $4 \mathrm{~d}$ and $5 \mathrm{~d}$ orbitals of the heavier transition metals relative to the $3 \mathrm{~d}$ orbitals. The orbital size effect manifests itself in many ways, including the $4 \mathrm{~d}$ and $5 \mathrm{~d}$ elements' preference for low-spin states, the ability to adopt higher oxidation states, and the propensity to form metal-metal multiple bonds, relative to the $3 \mathrm{~d}$ elements. Laboratory researchers concerned with the practicalities of chemical synthesis, however, also tend to be keenly aware of the differences between $4 \mathrm{~d}$ and $5 \mathrm{~d}$ elements. They may be aware, for example, that the synthesis of analogous $4 \mathrm{~d}$ and $5 \mathrm{~d}$ compounds often requires different reaction conditions, such as different reagents and solvents. From a more quantitative perspective, analogous reactions involving $4 \mathrm{~d}$ and $5 \mathrm{~d}$ compounds routinely exhibit major differences in kinetic and thermodynamic parameters. Relativistic effects, which significantly destabilize the $5 \mathrm{~d}$ orbitals of third-row transition elements relative to the $4 \mathrm{~d}$ orbitals of secondrow transition elements, are thought to account for a significant fraction of these differences. ${ }^{2,3}$ Herein, using isoelectronic, structurally characterized ruthenium and osmium corrole dimers as paradigms, we present a study of relativistic effects on metal-metal multiple bonds.

The relativistic effect $(\Delta P)$ on a molecular property $P$, such as an ionization potential or a bond distance, is defined as the difference between relativistic $\left(P_{\text {rel }}\right)$ and nonrelativistic $\left(P_{\text {nrel }}\right)$ calculated values of that property. Relativistic effects, accordingly, are purely theoretical quantities. For $\Delta P$ to be meaningful in a practical sense, however, we need to ensure that $P_{\text {rel }}$ is calculated at a high enough level so that it matches the experimental value of the property $P_{\text {expt }}$ and that $P_{\text {nrel }}$ is calculated at essentially the same theoretical level except for the relativistic treatment. Under these conditions, i.e., $P_{\text {expt }}=P_{\text {nrel}}$, we may with some justification speak about the relativistic effect on an experimentally determined property $P_{\text {expt }}$ or, more briefly, an experimentally calibrated relativistic effect. Fortunately, density functional theory (DFT) often provides both a computationally expedient and a surprisingly accurate description of relativistic effects on heavy element compounds. $4,5,6,7,8,9,10,11$

We hypothesized that $5 \mathrm{~d}-5 \mathrm{~d}$ multiple bonds should provide particularly good examples of strong relativistic effects. Since Ru corrole dimers are already known, ${ }^{12,13,14,15}$ Os corrole dimers appeared to be logical targets for synthesis and detailed characterization. Moreover, Os corrole chemistry is still in its infancy, with $\mathrm{Os}^{\mathrm{VI}} \mathrm{N}$ corroles as the only known representatives. ${ }^{16}$ Like certain other $5 \mathrm{~d}$ metallocorroles, ${ }^{17,18,19,20,21} \mathrm{Os}^{\mathrm{VI}} \mathrm{N}$ corroles also exhibit near-IR phosphorescence 
and have been applied as optical sensors for oxygen and as sensitizers for triplet-triplet annihilation upconversion. $^{22}$ Thus motivated, we duly synthesized a series of Os corrole dimers. Comparison with the analogous $\mathrm{Ru}$ compounds indeed revealed substantial relativistic effects for the Os series.

Results and discussion. (a) Synthesis and proof of composition. Two isoelectronic series of metal-metal-bonded dimers, $\{\mathrm{M}[\mathrm{T} p \mathrm{XPC}]\}_{2}$, were prepared, where $\mathrm{M}=\mathrm{Ru}$ and Os and $\mathrm{H}_{3}[\mathrm{~T} p \mathrm{XPC}]$ refers to a free-base meso-tris $\left(p\right.$-X-phenyl)corroles $\left(\mathrm{H}_{3}[\mathrm{~T} p \mathrm{XPC}], \mathrm{X}=\mathrm{CF}_{3}, \mathrm{H}, \mathrm{CH}_{3}\right.$, and $\mathrm{OCH}_{3}$ ). The $\mathrm{Ru}$ series could be accessed via minor modification of an existing synthetic protocol, namely from free-base corroles and $\left[\mathrm{Ru}(\operatorname{cod}) \mathrm{Cl}_{2}\right]_{\mathrm{x}}$ in refluxing 2-methoxyethanol in the presence of an amine base. ${ }^{12-14}$ A new protocol, however, had to be developed for the Os dimers, which in its final, optimized form involved the interaction of a free-base corrole, $\mathrm{Os}_{3}(\mathrm{CO})_{12}$, and potassium carbonate in 1,2,4-trichlorobenzene under an inert atmosphere at $180{ }^{\circ} \mathrm{C}$ over $\sim 16 \mathrm{~h}$ (Figure 1). Upon completion of the reaction (as indicated by UV-vis spectroscopy), highresolution electrospray ionization mass spectrometric analysis indicated the formation of Os corrole dimers. Upon cooling, the reaction mixture was subjected to column chromatography, affording the desired complexes as reddish-brown solids in $35-40 \%$ yields.

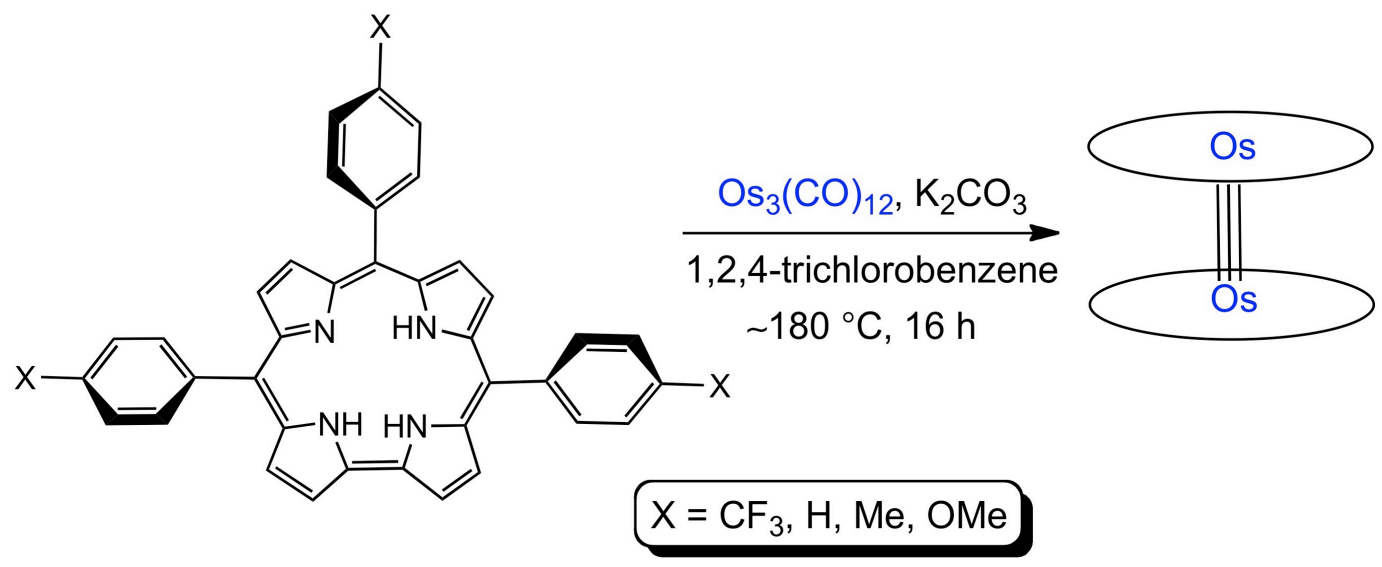

Figure 1. Synthesis of Os corrole dimers. 
The complexes yielded broad ${ }^{1} \mathrm{H}$ NMR spectra at room temperature, but the spectra sharpened significantly at $253 \mathrm{~K}$ (Figure 2), clearly indicating the compounds as diamagnetic. The diamagnetism of the compounds is consistent with Cotton's molecular orbital (MO) model of d-d metal-metal bonding, ${ }^{23}$ which predicts an Os-Os triple bond with a $\sigma^{2} \pi^{4} \delta^{2} \delta^{*}$ configuration. It may recalled that the analogous Group 8 metal-metal-bonded porphyrins are paramagnetic, triplet species with a $\sigma^{2} \pi^{4} \delta^{2} \delta^{* 2} \pi^{* 2}$ configuration. ${ }^{24,25,26}$ The ${ }^{1} \mathrm{H}$ NMR spectra at $253 \mathrm{~K}$ could be essentially fully assigned, revealing symmetry-related meso-triarylcorrole ligands in which the ortho and meta protons of each phenyl ring are split into symmetry-distinct pairs; the latter feature is typical for square-pyramidally coordinated corrole derivatives. ${ }^{27}$

(a)
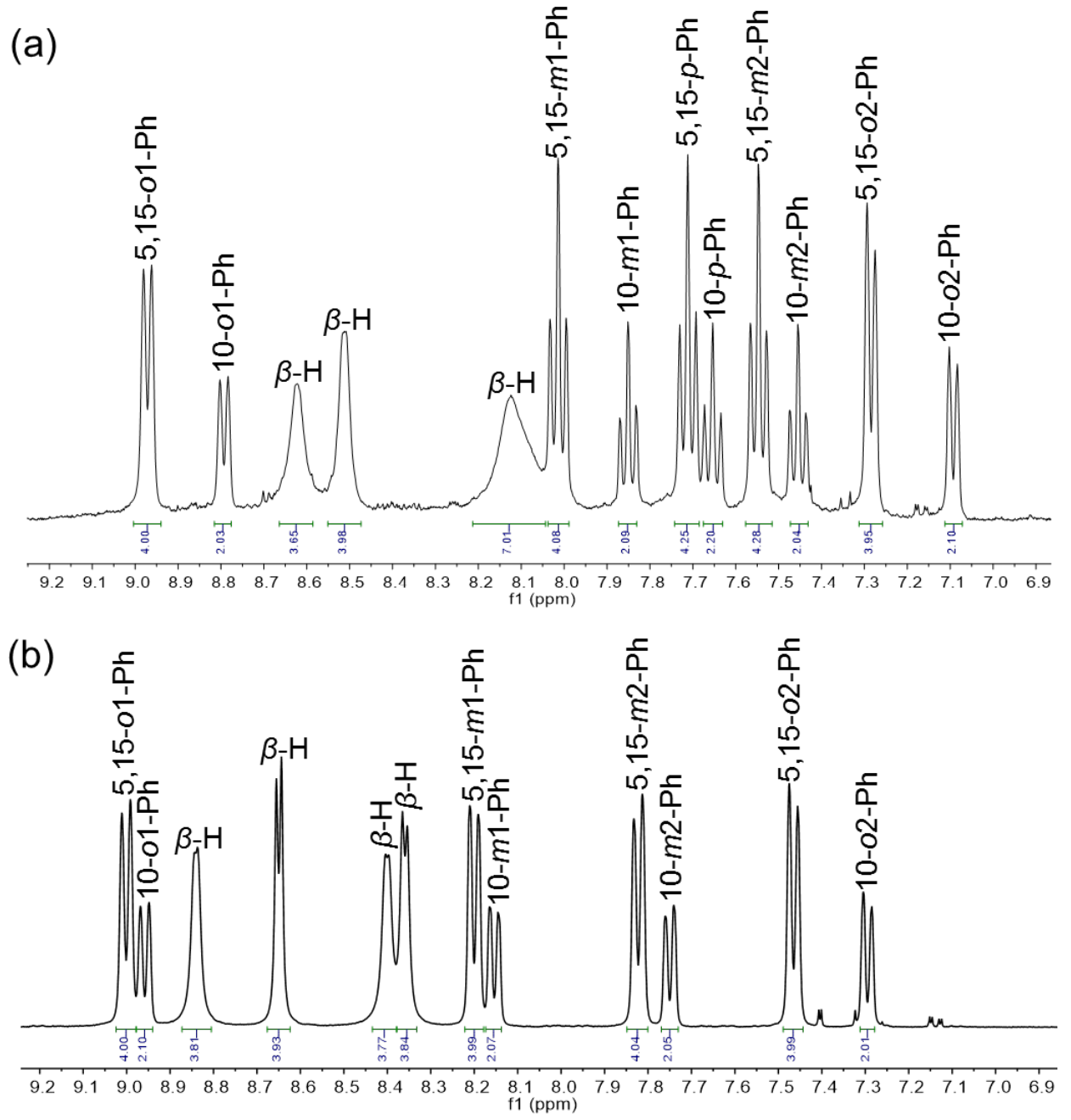

Figure 2. Representative ${ }^{1} \mathrm{H}$ NMR spectra in $\mathrm{CD}_{2} \mathrm{Cl}_{2}$ at $253 \mathrm{~K}$ : (a) $\{\mathrm{Os}[\mathrm{TPC}]\}_{2}$ and (b) $\left\{\mathrm{Os}\left[\mathrm{T} p \mathrm{CF}_{3} \mathrm{PC}\right\}_{2}\right.$. 
(b) X-ray crystal structures. Conclusive proof of structure came from three single-crystal X-ray structures, as detailed in Tables 1 and 2 and Figure 3. All three structures are characterized by approximately inversion-related corrole rings and approximately eclipsed Os-N bonds. Such a conformation allows for $\delta$-bonding between the $\mathrm{Ru}\left(\mathrm{d}_{\mathrm{xy}}\right)$ orbitals and also minimizes steric repulsions among the phenyl substituents. The three structures also exhibit mutually consistent Os-N $(1.95 \pm 0.05 \AA)$ and Os-Os $(\sim 2.24 \AA)$ distances and Os- $\mathrm{N}_{\text {plane }}$ displacements $(\sim 0.51 \AA)$. Interestingly, while the $\mathrm{M}-\mathrm{N}$ and $\mathrm{M}-\mathrm{N}_{\text {plane }}$ distances are nearly identical for $\mathrm{Ru}$ and Os corrole dimers, the Os-Os distances are significantly longer than the Ru-Ru distances ( $2.18 \AA$, Table 2$)$. The difference of $\sim 0.06 \AA$ between the Ru-Ru and Os-Os distances is slightly lower than that expected on the basis of Pyykkö's triple bond radii for the two metals (Ru $1.03 \AA$ and Os 1.09 Å), which, importantly, were not 'trained' on metal-metal bonded compounds. An interesting question concerns to what extent these metal-metal bond distances are affected by relativistic effects. B3LYP ${ }^{28,29,30}-\mathrm{D} 3^{31} / \mathrm{STO}-\mathrm{TZP}$ geometry optimizations of $\{\mathrm{Os}[\mathrm{TPC}]\}_{2}$ with nonrelativistic and zeroth order regular approximation (ZORA) ${ }^{32,33}$ scalar-relativistic Hamiltonians yielded very similar Os-Os distances -2.255 and $2.262 \AA$, respectively. The limited amount of computational data in the literature also suggests that relativistic effects should only have a minor influence on $4 \mathrm{~d}-4 \mathrm{~d}$ and $5 \mathrm{~d}-5 \mathrm{~d}$ metal-metal bonds. ${ }^{34,35,36,37}$

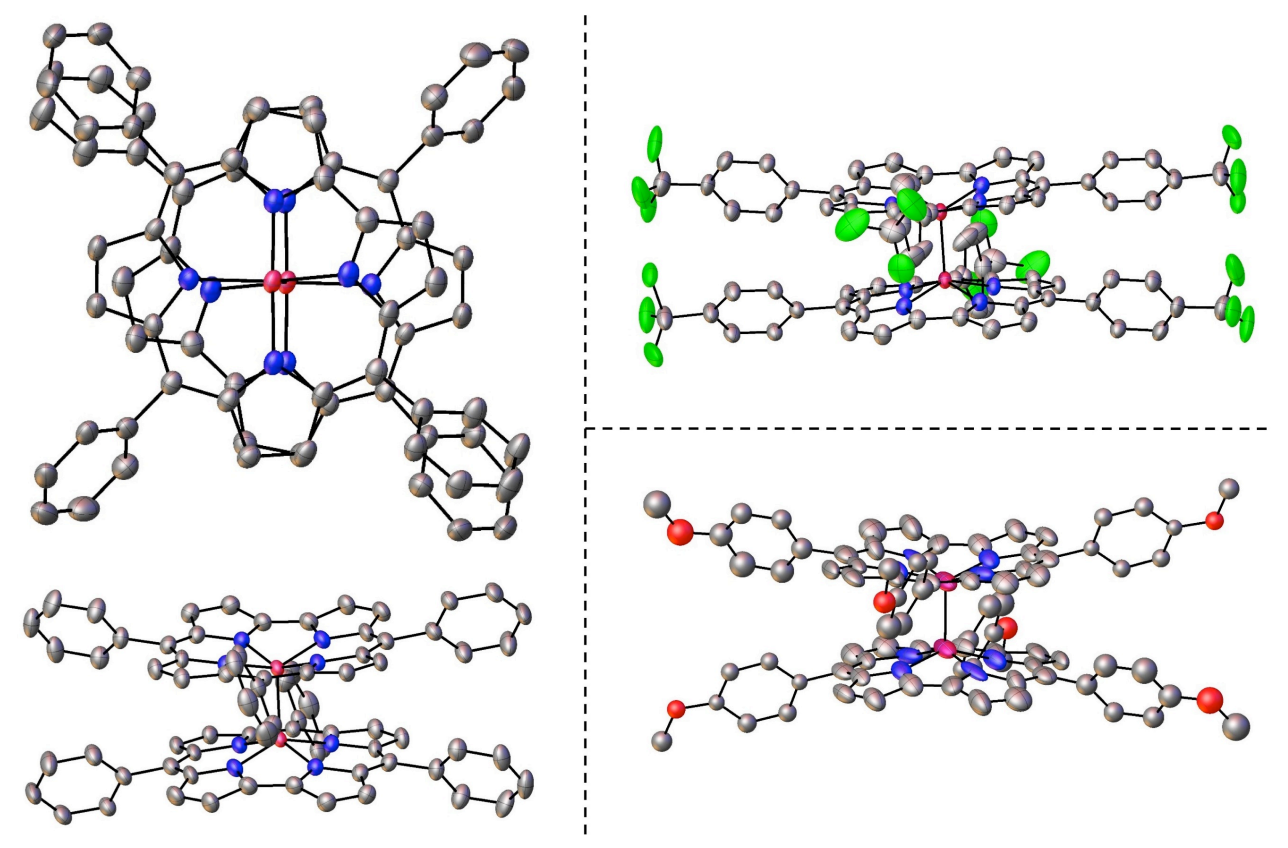

Figure 3. Thermal ellipsoid plots (50\%) for $\{\mathrm{Os}[\mathrm{TPC}]\}_{2}$ (left), $\left\{\mathrm{Os}\left[\mathrm{T} p \mathrm{CF}_{3} \mathrm{C}\right]\right\}_{2}$ (top right), and $\left\{\mathrm{Os}\left[\mathrm{T} p \mathrm{OCH}_{3} \mathrm{C}\right]\right\}_{2}$. 
Table 1. Crystallographic data for the complexes analyzed.

\begin{tabular}{|c|c|c|c|}
\hline Sample & $\left\{\mathrm{Os}\left[\mathrm{T} p \mathrm{CF}_{3} \mathrm{C}\right]\right\}_{2}$ & $\{\mathrm{Os}[\mathrm{TPC}]\}_{2}$ & $\{\mathrm{Os}[\mathrm{T} p \mathrm{OMeC}]\}_{2}$ \\
\hline Chemical formula & $\mathrm{C}_{92} \mathrm{H}_{68} \mathrm{~F}_{18} \mathrm{~N}_{8} \mathrm{Os}_{2}$ & $\mathrm{C}_{148} \mathrm{H}_{92} \mathrm{~N}_{16} \mathrm{Os}_{3.41}$ & $\mathrm{C}_{80} \mathrm{H}_{58} \mathrm{~N}_{8} \mathrm{O}_{6} \mathrm{Os}_{2}$ \\
\hline Formula mass & 2007.94 & 2743.66 & 1607.74 \\
\hline Crystal system & Triclinic & Triclinic & Triclinic \\
\hline Crystal size $\left(\mathrm{mm}^{3}\right)$ & $0.270 \times 0.080 \times 0.005$ & $0.150 \times 0.050 \times 0.010$ & $0.140 \times 0.020 \times 0.010$ \\
\hline Space group & $P-1$ & $P-1$ & $P-1$ \\
\hline$\lambda(\AA)$ & 0.7749 & 0.7749 & 0.8856 \\
\hline$a(\AA)$ & $9.625(3)$ & $12.8033(7)$ & $11.4553(6)$ \\
\hline$b(\AA)$ & $15.330(5)$ & $13.0678(7)$ & $12.4466(7)$ \\
\hline$c(\AA)$ & $16.018(6)$ & $17.0021(9)$ & $12.9535(8)$ \\
\hline$\alpha(\operatorname{deg})$ & $111.503(7)$ & $101.482(2)$ & $71.171(4)$ \\
\hline$\beta(\operatorname{deg})$ & $96.578(7)$ & $101.895(2)$ & $80.750(4)$ \\
\hline$\gamma(\operatorname{deg})$ & $101.453(7)$ & $105.645(2)^{\circ}$ & $83.551(4)$ \\
\hline$Z$ & 1 & 1 & 1 \\
\hline$V\left(\AA^{3}\right)$ & 2109.1(13) & $2580.7(2)$ & $1721.72(18)$ \\
\hline Temperature (K) & $100(2)$ & $100(2)$ & $100(2)$ \\
\hline Density $\left(\mathrm{g} / \mathrm{cm}^{3}\right)$ & 1.581 & 1.765 & 1.551 \\
\hline Measured reflections & 81222 & 68853 & 9809 \\
\hline Unique reflections & 8595 & 10596 & 4483 \\
\hline Parameters & 596 & 661 & 442 \\
\hline Restraints & 116 & 9 & 232 \\
\hline$R_{\text {int }}$ & 0.0581 & 0.0407 & 0.0682 \\
\hline$\theta$ range (deg.) & $1.522-28.999$ & $1.833-29.018$ & $2.159-28.520$ \\
\hline$R_{1}, w R_{2}$ all data & $0.0418,0.1062$ & $0.0408,0.1045$ & $0.1088,0.1642$ \\
\hline$S(\mathrm{GooF})$ all data & 1.069 & 1.083 & 1.054 \\
\hline Max/min res. dens. $\left(\mathrm{e} / \AA^{3}\right)$ & $2.612 /-1.672$ & $3.140 /-1.431$ & $2.524 /-1.148$ \\
\hline
\end{tabular}

Table 2. Selected crystallographic distances ( $\AA$ ) relevant to the osmium coordination geometry.

\begin{tabular}{lrrrrrr}
\hline Complex & Os-N1 & Os-N2 & Os-N3 & Os-N4 & Os-Os & Os-N plane \\
\hline$\left\{\mathrm{Os}\left[\mathrm{T} p \mathrm{CF}_{3} \mathrm{C}\right]\right\}_{2}$ & $1.979(4)$ & $2.002(4)$ & $1.991(4)$ & $1.977(4)$ & $2.2398(7)$ & $0.522(2)$ \\
& $1.959(4)$ & $1.979(4)$ & $1.978(4)$ & $1.968(4)$ & $2.2346(4)$ & $0.507(2)$ \\
$\{\mathrm{Os}[\mathrm{TPC}]\}_{2}$ & $1.961(6)$ & $1.960(7)$ & $1.963(6)$ & $1.951(7)$ & $2.2403(5)$ & $0.519(3)$ \\
& $1.910(16)$ & $1.979(12)$ & $1.945(14)$ & $1.959(12)$ & $2.2291(13)$ & $-0.510(5)$
\end{tabular}


Table 3. Optical spectroscopic and electrochemical properties of $\{\mathrm{Ru}[\mathrm{T} p \mathrm{XPC}]\}_{2}$ and $\{\mathrm{Os}[\mathrm{T} p \mathrm{XPC}]\}_{2}: \lambda_{\max }(\mathrm{nm})$ for Soret and $\mathrm{Q}$ bands and $E_{1 / 2}$ values $(\mathrm{V})$.

\begin{tabular}{|c|c|c|c|c|c|c|c|c|c|}
\hline Complex & $\lambda_{\max }$ & Q & $E_{1 / 20 \times 4}$ & $E_{1 / 20 \times 3}$ & $E_{1 / 20 \times 2}$ & $E_{1 / 20 \times 1}$ & $E_{1 / 2 \text { red1 }}$ & $E_{1 / 2 \text { red2 }}$ & $\Delta E$ \\
\hline$\left\{\mathrm{Ru}\left[\mathrm{T} p \mathrm{CF}_{3} \mathrm{PC}\right]\right\}_{2}$ & 328,397 & 541 & - & 1.31 & 1.09 & 0.76 & -0.63 & -1.43 & 1.39 \\
\hline$\{\mathrm{Ru}[\mathrm{TPC}]\}_{2}$ & 328,397 & 539 & 1.56 & 1.23 & 0.99 & 0.55 & -0.86 & -1.66 & 1.41 \\
\hline$\left\{\mathrm{Ru}\left[\mathrm{T} p \mathrm{CH}_{3} \mathrm{PC}\right]\right\}_{2}$ & 329,398 & 538 & 1.44 & 1.18 & 0.98 & 0.52 & -0.85 & - & 1.37 \\
\hline$\left\{\mathrm{Ru}\left[\mathrm{T} p \mathrm{OCH}_{3} \mathrm{PC}\right]\right\}_{2}$ & 329,406 & 533 & 1.33 & 1.14 & 0.92 & 0.50 & -0.86 & - & 1.36 \\
\hline$\left\{\mathrm{Os}\left[\mathrm{T} p \mathrm{CF}_{3} \mathrm{PC}\right]\right\}_{2}$ & 287,407 & 583 & - & 1.28 & 1.01 & 0.79 & -1.13 & -1.54 & 1.92 \\
\hline$\{\mathrm{Os}[\mathrm{TPC}]\}_{2}$ & 287,405 & 584 & - & 1.15 & 0.93 & 0.60 & -1.29 & -1.69 & 1.89 \\
\hline$\left\{\mathrm{Os}\left[\mathrm{T} p \mathrm{CH}_{3} \mathrm{PC}\right]\right\}_{2}$ & 287,407 & 584 & 1.35 & 1.09 & 0.88 & 0.55 & -1.31 & -1.72 & 1.86 \\
\hline$\left\{\mathrm{Os}\left[\mathrm{T} p \mathrm{OCH}_{3} \mathrm{PC}\right]\right\}_{2}$ & 286,407 & 585 & 1.28 & 1.05 & 0.85 & 0.54 & -1.32 & -1.73 & 1.86 \\
\hline
\end{tabular}

(c) Electrochemistry. The cyclic voltammograms of both the Ru and Os corrole dimers exhibit at least three reversible oxidations and two reversible reductions (Table 3 and Figure 4). The oxidation potentials $E_{1 / 20 \times 1}$ through $E_{1 / 20 \times 3}$ turned out to be very similar for the Ru and Os dimers, as expected for ligand-centered processes. The reduction potentials, on the other hand, were found to be dramatically lower for the Os series (i.e., they are harder to reduce), downshifted by essentially $0.5 \mathrm{~V}$ relative to the $\mathrm{Ru}$ series, strongly implicating the metal center as the site of reduction. Essentially the same downshift is also observed for the oxidation potentials of Os porphyrin dimers (i.e., they are easier to oxidize) relative to their ruthenium counterparts. $^{24-26}$ The question thus arises as to what fraction of this downshift is attributable to differences in relativistic effects for the two metals.

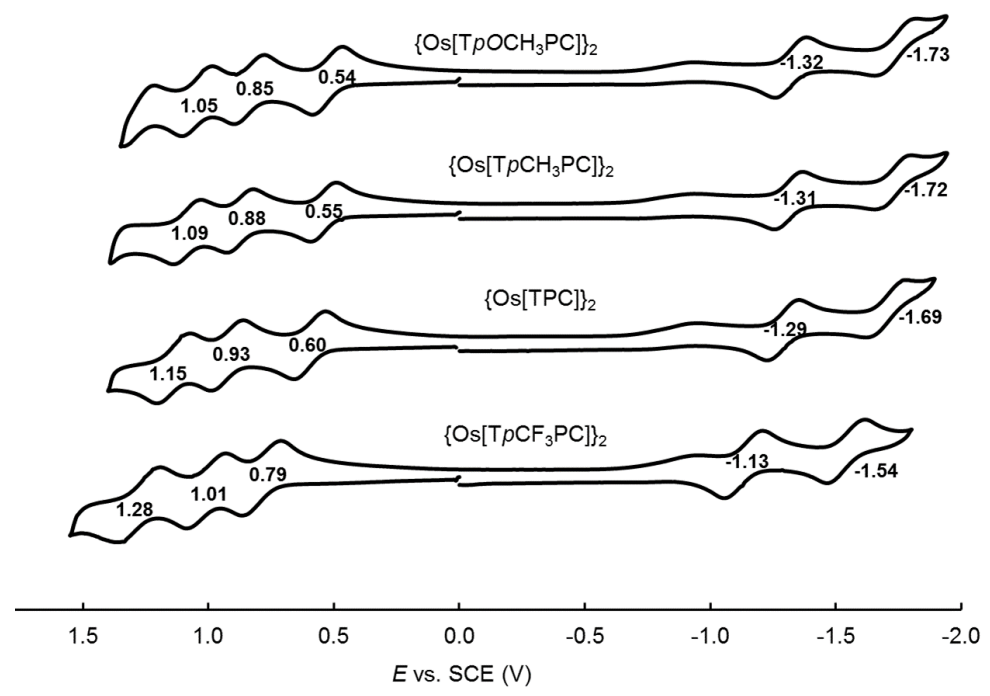

Figure 4. Cyclic voltammograms of $\{\mathrm{Os}[\mathrm{T} p \mathrm{XPC}]\}_{2}$ in dichloromethane containing 0.1 M TBAP. 
B3LYP-D3/STO-TZP calculations of the adiabatic ionization potentials of $\{\mathrm{Ru}[\mathrm{TPC}]\}_{2}$ and $\{\mathrm{Os}[\mathrm{TPC}]\}_{2}$ yielded nearly identical values of $5.40 \pm 0.05 \mathrm{eV}$, regardless of relativistic treatment, consistent with ligand-centered ionization, as surmised above. The adiabatic electron affinities of the two complexes, in contrast, proved to be significantly different at both the nonrelativistic and scalar-relativistic levels. With a nonrelativistic Hamiltonian, the adiabatic EAs turned out to be $2.642 \mathrm{eV}$ for $\{\mathrm{Ru}[\mathrm{TPC}]\}_{2}$ and $2.368 \mathrm{eV}$ for $\{\mathrm{Os}[\mathrm{TPC}]\}_{2}$. With the zeroth order regular approximation to the Dirac equation applied as a scalar approximation, the relativistic adiabatic EAs turned out to be $2.501 \mathrm{eV}$ for $\{\mathrm{Ru}[\mathrm{TPC}]\}_{2}$ and $1.957 \mathrm{eV}$ for $\{\mathrm{Os}[\mathrm{TPC}]\}_{2}$. Key lessons from these results include the following: The relativistic effect on the adiabatic EA is significant for $\{\mathrm{Ru}[\mathrm{TPC}]\}_{2}(0.14 \mathrm{eV})$ but nearly three times higher for $\{\mathrm{Os}[\mathrm{TPC}]\}_{2}(0.41 \mathrm{eV})$. Second, even at the nonrelativistic level, the adiabatic EA of $\{\mathrm{Os}[\mathrm{TPC}]\}_{2}$ is $0.27 \mathrm{eV}$ lower than that of $\{\mathrm{Ru}[\mathrm{TPC}]\}_{2}$, but the difference increases to just over $0.40 \mathrm{eV}$ at the relativistic level, in fair agreement with the difference in experimental reduction potentials of the two compounds. The results suggest that about a third of the difference in reduction potentials between Ru and Os may be attributed to differential relativistic effects between the two elements. Based on comparative electrochemical measurements of Mo and W biscorrole sandwich compounds, ${ }^{38,39,40}$ however, we expected a somewhat larger relativistic effect for the reduction potential of $\{\mathrm{Os}[\mathrm{TPC}]\}_{2}$ as well as for the differential relativistic effect between $\{\mathrm{Ru}[\mathrm{TPC}]\}_{2}$ and $\{\mathrm{Os}[\mathrm{TPC}]\}_{2}$. An examination of the scalar-relativistic spin density profiles of the ionized states of the two complexes provided a plausible explanation for the somewhat muted relativistic effect in the Os case (Figure 5).

For the cationic states of both $\{\mathrm{Ru}[\mathrm{TPC}]\}_{2}$ and $\{\mathrm{Os}[\mathrm{TPC}]\}_{2}$, the spin density was found to be entirely localized on the ligands, in agreement with the discussion above. The spin density corresponds to electron removal from a corrole " $\mathrm{a}_{2 \mathrm{u}}$ "-based HOMO of the dimeric molecules, permitting ourselves to use the $D_{4 \mathrm{~h}}$ irreducible representation that is appropriate for the analogous porphyrin HOMO. For $\{\mathrm{Ru}[\mathrm{TPC}]\}_{2}$ anion, on the other hand, the spin density is largely $(\sim 80 \%)$ localized on the $\mathrm{Ru}$ atoms, consistent with single occupancy of one of the $\mathrm{Ru}-\mathrm{Ru}$ $\pi^{*}$-based MOs, which accounts for the significant relativistic effect on the EA. For $\{\mathrm{Os}[\mathrm{TPC}]\}_{2}$ anion, in contrast, the spin density is split approximately 1:1 between the $\mathrm{Os}_{2}$ moiety and the TPC ligands. The relativistically elevated energy of the Os(5d) orbitals apparently pushes part of the spin density over to a corrole-based MO of the appropriate symmetry, as qualitatively illustrated by the LUMO of $\{\mathrm{Os}[\mathrm{TPC}]\}_{2}$ (Figure 5). The finding that one-electron reduction does 
not occur in a predominantly metal-centered manner nicely explains why the relativistic effect on the reduction potential of $\{\mathrm{Os}[\mathrm{TPC}]\}_{2}$, while substantial, is not quite as dramatic as might have been anticipated.
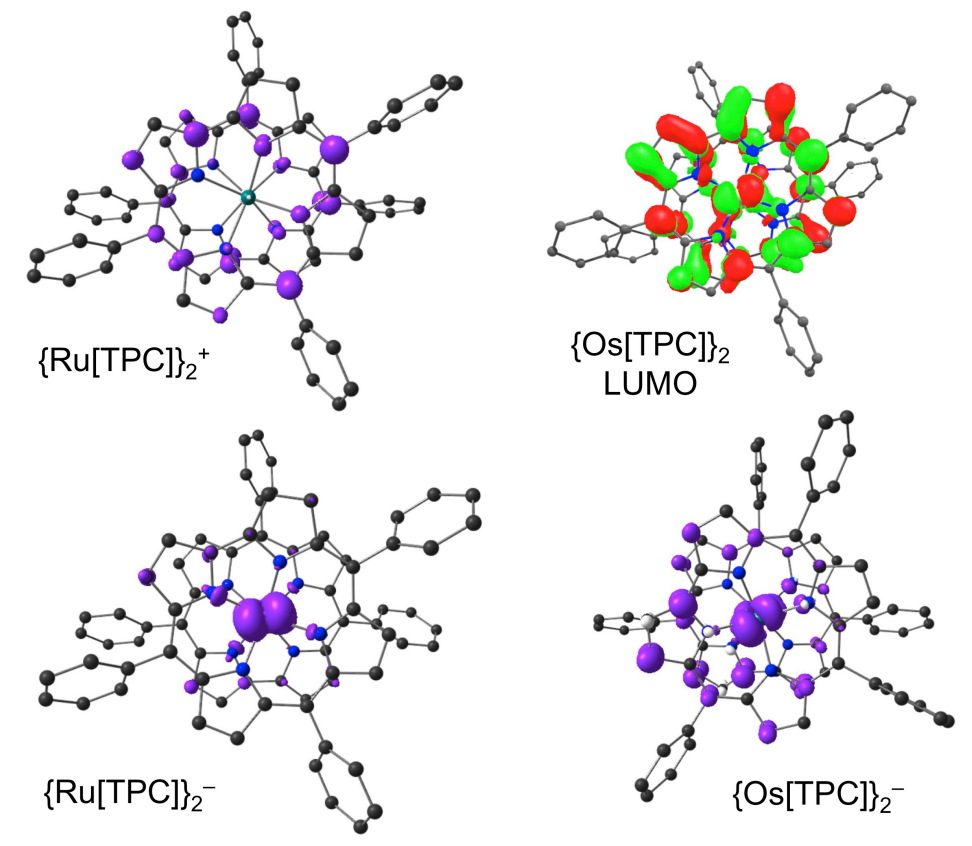

Figure 5. Selected scalar relativistic B3LYP-D3/ZORA-STO-TZP spin density and MO plots.

UV-visible spectroscopy. For isoelectronic compounds, the $\{\mathrm{Ru}[\mathrm{T} p \mathrm{XPC}]\}_{2}$ and $\{\mathrm{Os}[\mathrm{T} p \mathrm{XPC}]\}_{2}$ series exhibit remarkably different UV-vis spectra (Figure 6). In our earlier work on metallocorroles, we have regularly used different para-X-substituted corrole derivatives as a probe for a noninnocent corrole ligand, which almost invariably manifests itself as a substituentsensitive Soret maximum. ${ }^{41}$ By this criterion, the Ru and Os corrole dimers, like the majority of $4 \mathrm{~d}$ and $5 \mathrm{~d}$ metallocorroles (including $\mathrm{MoO},{ }^{42} \mathrm{RuN},{ }^{14} \mathrm{OsN},{ }^{16} \mathrm{TcO},{ }^{43} \mathrm{ReO},{ }^{44} \mathrm{Pt},{ }^{45}$ and $\mathrm{Au}^{46,47,48,49}$ corroles), appear to be innocent. The spectra of both series of dimers are nonetheless unusual, relative to first-row transition metal corroles, and are characterized by intense near-UV features. Thus, both the Ru and Os series exhibit Soret-like bands at $\sim 400 \mathrm{~nm}$ and intense higher-energy "post-Soret" bands. The latter feature occurs at $\sim 328 \mathrm{~nm}$ for the Ru series and at $\sim 287 \mathrm{~nm}$ for the Os series, which corresponds to an energy difference of $\sim 0.55 \mathrm{eV}$. In addition, the Os series exhibits a third well-resolved peak in the near-UV region at $\sim 363 \mathrm{~nm}$. The Ru series also exhibits well-resolved Q band at $537 \pm 4 \mathrm{~nm}$, which appears to exhibit slight substituent-dependence, while the Q bands of the Os series only appear as a less distinct feature at around $590 \mathrm{~nm}$. 

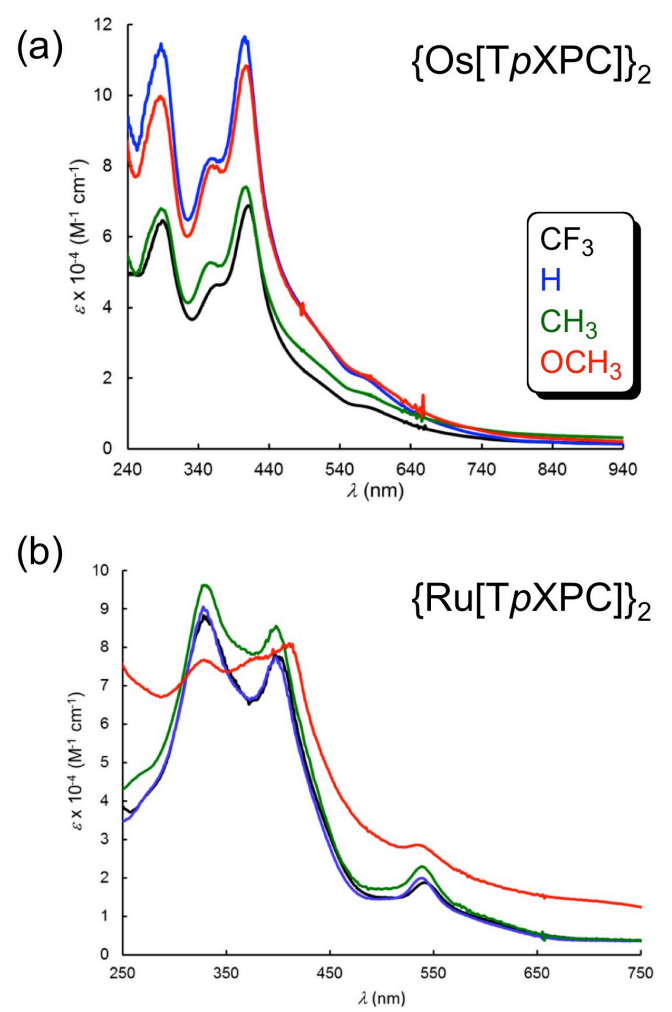

Figure 6. UV-vis spectra of (a) $\{\mathrm{Os}[\mathrm{T} p \mathrm{XPC}]\}_{2}$ and (b) $\{\mathrm{Ru}[\mathrm{T} p \mathrm{XPC}]\}_{2}$ in dichloromethane.

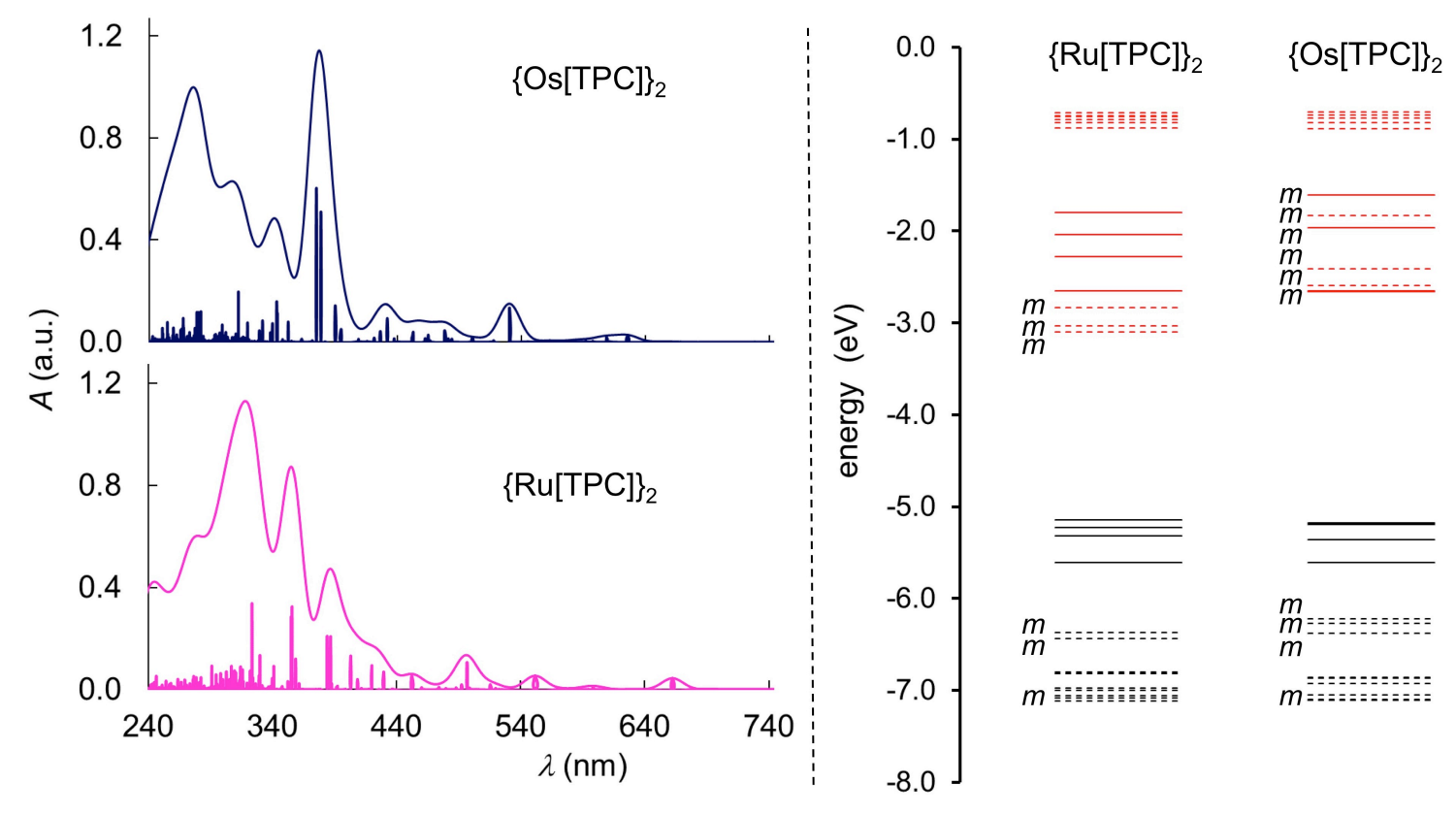

Figure 7. Left: Scalar-relativistic ZORA-TDDFT (B3LYP-D3/STO-TZP) simulated spectra for $\{\mathrm{Ru}[\mathrm{TPC}]\}_{2}$ and $\{\mathrm{Os}[\mathrm{TPC}]\}_{2}$ (left) and the corresponding Kohn-Sham energy level diagrams (right). Solid and dotted lines indicate Gouterman-type and other MOs, respectively, while the label $m$ denotes greater than $20 \%$ metal character. 
Scalar-relativistic time-dependent density functional theory (TDDFT; B3LYPD3/ZORA-STO-TZP) calculations do a rather good job of reproducing key features of the UVvis spectra of $\{\mathrm{Ru}[\mathrm{TPC}]\}_{2}$ and $\{\mathrm{Os}[\mathrm{TPC}]\}_{2}$, including the blue-shifted post-Soret feature of the multiplicity of individual MO-to-MO excitations contributing to each transition. The scalar-latter (Figure 7). A detailed discussion of peak assignments, however, is impractical, not only because of the large number of transitions within a given spectral region, but also because of the relativistic MO energy levels of the two compounds, however, readily permit a discussion of relativistic effects. There is little difference in the orbital energy levels for the few highest occupied MOs of the two complexes, which consist of combinations of the Gouterman-type HOMOs of the two corroles. ${ }^{50,51}$ Likewise, purely Gouterman-type LUMOs have similar orbital energies for the two molecules. On the other hand, LUMOs with significant or predominant metal d character are destabilized in $\{\mathrm{Os}[\mathrm{TPC}]\}_{2}$ by as much $0.5-1.0 \mathrm{eV}$, relative to $\{\mathrm{Ru}[\mathrm{TPC}]\}_{2}$. Comparison with an analogous nonrelativistic MO energy level diagram (not shown) showed that the differences between Ru and Os energy levels are largely attributable to much stronger relativistic effects for Os $5 \mathrm{~d}$ orbitals. A detailed examination of the MO-to-MO composition of the transitions in different spectral regions further confirmed that relativistically destabilized Os 5d-based MOs indeed account for much of the intensity of the unique, blueshifted post-Soret peak of $\{\mathrm{Os}[\mathrm{TPC}]\}_{2}$.

Conclusion. The $4 \mathrm{~d}$ and $5 \mathrm{~d}$ metallocorroles are a novel class of size-mismatched complexes incorporating a large transition metal ion within the sterically constrained $\mathrm{N}_{4}$ cavity of a corrole. The metal insertion process is almost invariably capricious, requiring specific reagents, solvents, and temperatures, but the products, once formed, are often stable, potentially allowing for a wide range of applications. Against this backdrop, we have presented the synthesis of osmium corrole dimers, which are only the second class of Os corrole derivatives ever to be reported. The compounds were obtained in fairly good yields, 35-46\%, which are roughly double those obtained for analogous $\mathrm{Ru}$ corrole dimers. Whether the new compounds prove amenable to reductive cleavage and thereby serve as a source of new mononuclear Os corrole complexes remains an exciting prospect for the future.

The availability analogous $\mathrm{Ru}$ and Os corrole dimers made for a detailed study of experimentally calibrated relativistic effects on Group 8 metallocorroles. Single-crystal X-ray structures of three Os corrole dimers revealed Os-Os distances of $\sim 2.24 \AA$, which are $\sim 0.06 \AA$ longer than the $\mathrm{Ru}-\mathrm{Ru}$ distances in analogous $\mathrm{Ru}$ corrole dimers. Interestingly, DFT geometry 
optimizations with scalar-relativistic and nonrelativistic Hamiltonians revealed an almost vanishingly small relativistic effect on these distances.

The redox potentials of the compounds and associated calculations on the gas-phase ionization potentials and electron affinities of the compounds provided some of the most significant insights into relativistic effects on the compounds. For a given corrole ligand, the $\mathrm{Ru}$ and Os dimers were found to exhibit very similar oxidation potentials, consistent with ligandcentered oxidation; the Os dimers on the other hand were found to exhibit substantially lower reduction potentials, by a margin of $0.5 \mathrm{eV}$, suggesting reduction of the metal-metal bond. Gasphase scalar-relativistic DFT calculations of ionization potentials and electron affinities nicely reproduced the trends in electrochemical data. In particular, the calculations suggested that about a third of the difference in reduction potential between analogous $\mathrm{Ru}$ and Os corrole dimers can be attributed to relativistic effects, which is somewhat smaller than what we expected. A plausible explanation is provided by scalar-relativistic spin density profiles, which indicate that one-electron reduction of the Os dimer does not occur exclusively on the metal-metal bond, but that as much as half the spin density is delocalized on to the corrole rings.

The $\mathrm{Ru}$ and Os corrole dimers exhibit significantly different electronic absorption spectra in the UV-vis regime, including an intense post-Soret feature in the case of the Os compounds that is some $0.55 \mathrm{eV}$ blue-shifted relative to the analogous feature for the Ru compounds. TDDFT calculations suggest that a large number of the transitions in this region have metal dbased LUMO character, which leads to a higher transition energy in the Os case, as a result of strong relativistic destabilization of the $\mathrm{Os}(5 \mathrm{~d})$ orbitals.

\section{Experimental section}

Materials. All free-base corroles were synthesized via the now-standard water-methanol method. ${ }^{52}$ The reagents 1,2,4-trichlorobenzene, triosmium dodecacarbonyl (99.99\%), potassium carbonate (granulated), 2-methoxyethanol, trimethylamine, and (1,5cyclooctadiene)ruthenium(II) polymer were purchased from Sigma-Aldrich and used as received. Silica gel 60 (0.04-0.063 mm particle size, 230-400 mesh, Merck) was employed for flash chromatography. Silica gel 60 preparative thin-layer chromatographic plates $(20 \mathrm{~cm}$ x $20 \mathrm{~cm} \mathrm{x}$ $0.5 \mathrm{~mm}$, Merck) were used for final purification of all complexes.

General instrumental methods. UV-visible spectra were recorded on an HP 8453 spectrophotometer. ${ }^{1} \mathrm{H}$ NMR spectra $\left(253 \mathrm{~K}, \mathrm{CD}_{2} \mathrm{Cl}_{2}\right)$ were recorded on a $400 \mathrm{MHz}$ Bruker 
Avance III HD spectrometer equipped with a $5 \mathrm{~mm} \mathrm{BB} / 1 \mathrm{H}$ SmartProbe and referenced to residual $\mathrm{CH}_{2} \mathrm{Cl}_{2}$ at $5.31 \mathrm{ppm}$. High-resolution electrospray-ionization (HR-ESI) mass spectra were recorded on an LTQ Orbitrap XL spectrometer, using methanolic solutions and typically in positive ion mode. Elemental analyses were performed by Atlantic Microlab Inc., U.S.A. ${ }^{53}$

Cyclic voltammetry was carried out at $298 \mathrm{~K}$ with an EG\&G Model 263A potentiostat equipped with a three-electrode system: a glassy carbon working electrode, a platinum wire counterelectrode, and a saturated calomel reference electrode (SCE). Tetra( $n$-butyl)ammonium perchlorate, recrystallized twice from absolute ethanol and dried in a desiccator for at least 2 weeks, was used as the supporting electrolyte. Anhydrous $\mathrm{CH}_{2} \mathrm{Cl}_{2}$ (Aldrich) was used as solvent. The reference electrode was separated from the bulk solution by a fritted-glass bridge filled with the solvent/supporting electrolyte mixture. The electrolyte solution was purged with argon for at least 2 min prior to all measurements, which were carried out under an argon blanket. All potentials were referenced to the SCE.

General procedure for the synthesis of $\{\mathbf{R u}[\mathbf{T} p \mathbf{X P C}]\}_{2}$. To a solution of the free-base corrole, $\mathrm{H}_{3}[\mathrm{~T} p \mathrm{XPC}]$ (0.136 mmol), in refluxing 2-methoxyethanol $(10 \mathrm{~mL})$ under argon, was added trimethylamine $(50 \mu \mathrm{L})$, followed by $\left\{\mathrm{Ru}(\mathrm{cod}) \mathrm{Cl}_{2}\right\}_{\times}(115 \mathrm{mg}, 0.41 \mathrm{mmol})$. After stirring for $30 \mathrm{~min}$, the reaction mixture was cooled to room temperature, the solvent was evaporated, and the resulting crude solid was purified by column chromatography on silica gel with 3:2 dichloromethane/hexane as eluent. For final characterization, the product was further purified by preparative thin-layer chromatography on silica gel with 3:1 dichloromethane/hexane as eluent.

$\left\{\mathbf{R u}\left[\mathbf{T} p \mathbf{C F}_{3} \mathbf{P C}\right]\right\}_{2}$. Yield $20.2 \mathrm{mg}(0.0122 \mathrm{mmol}, 17.9 \%)$. UV-vis $\left(\mathrm{CH}_{2} \mathrm{Cl}_{2}\right) \lambda_{\max }(\mathrm{nm})$ and $\varepsilon \times 10^{-4}\left(\mathrm{M}^{-1} \mathrm{~cm}^{-1}\right): 328(8.83), 397$ (7.82), 541(1.88). ${ }^{1} \mathrm{H}$ NMR (400 MHz, $\left.-20^{\circ} \mathrm{C}\right): \delta 9.10(\mathrm{~d}$, $\left.2 \mathrm{H},{ }^{3} J_{\mathrm{HH}}=8.0 \mathrm{~Hz}, 10-o 1-\mathrm{Ph}\right) ; 8.99\left(\mathrm{~d}, 4 \mathrm{H},{ }^{3} J_{\mathrm{HH}}=8.0 \mathrm{~Hz}, 5,15-o 1-\mathrm{Ph}\right) ; 8.83\left(\mathrm{~d}, 4 \mathrm{H},{ }^{3} J_{\mathrm{HH}}=3.5\right.$ $\mathrm{Hz}, \beta-\mathrm{H}) ; 8.66\left(\mathrm{~d}, 4 \mathrm{H},{ }^{3} J_{\mathrm{HH}}=4.2 \mathrm{~Hz}, \beta-\mathrm{H}\right) ; 8.35(\mathrm{bs}, 8 \mathrm{H}, \beta-\mathrm{H}) ; 8.15$ (overlapping d, $6 \mathrm{H},{ }^{3} J_{\mathrm{HH}}=$ $9.5 \mathrm{~Hz}, 10-m 1-\mathrm{Ph} \& 5,15-m 1-\mathrm{Ph}) ; 7.86\left(\mathrm{~d}, 4 \mathrm{H},{ }^{3} J_{\mathrm{HH}}=8.0 \mathrm{~Hz}, 5,15-o 2-\mathrm{Ph}\right) ; 7.80\left(\mathrm{~d}, 2 \mathrm{H},{ }^{3} J_{\mathrm{HH}}=\right.$ $8.5 \mathrm{~Hz}, 10-o 2-\mathrm{Ph}) ; 7.53\left(\mathrm{~d}, 4 \mathrm{H},{ }^{3} J_{\mathrm{HH}}=8.0 \mathrm{~Hz}, 5,15-m 2-\mathrm{Ph}\right) ; 7.37\left(\mathrm{~d}, 2 \mathrm{H},{ }^{3} J_{\mathrm{HH}}=7.7 \mathrm{~Hz}, 10-m 2-\right.$ $\mathrm{Ph}$ ). HRMS (ESI): $\mathrm{M}^{+}=1658.1185$ (expt), 1658.1202 (calcd for $\mathrm{C}_{80} \mathrm{H}_{40} \mathrm{~F}_{18} \mathrm{~N}_{8} \mathrm{Ru}_{2}$, major isotopomer). Elemental analysis (\%): found C 57.69, H 2.62, N 6.32; calcd C 57.98, H 2.43, N 6.76.

$\{\mathbf{R u}[\mathbf{T P C}]\}_{2}$. Yield $15.0 \mathrm{mg}(0.0119 \mathrm{mmol}, 17.6 \%)$. UV-vis $\left(\mathrm{CH}_{2} \mathrm{Cl}_{2}\right) \lambda_{\max }(\mathrm{nm})$ and $\varepsilon \mathrm{x}$ $10^{-4}\left(\mathrm{M}^{-1} \mathrm{~cm}^{-1}\right): 328$ (9.06), 397 (7.74), $539(1.99) .{ }^{1} \mathrm{H}$ NMR $\left(400 \mathrm{MHz},-20^{\circ} \mathrm{C}\right): \delta 9.05(\mathrm{~d}, 4 \mathrm{H}$, $\left.{ }^{3} J_{\mathrm{HH}}=7.2 \mathrm{~Hz}, 5,15-o 1-\mathrm{Ph}\right) ; 8.93\left(\mathrm{~d}, 2 \mathrm{H},{ }^{3} J_{\mathrm{HH}}=8.2 \mathrm{~Hz}, 10-o 1-\mathrm{Ph}\right) ; 8.77$ (bs, $\left.4 \mathrm{H}, \beta-\mathrm{H}\right) ; 8.60$ (bs, 
$4 \mathrm{H}, \beta-\mathrm{H}) ; 8.29(\mathrm{bs}, 8 \mathrm{H}, \beta-\mathrm{H}) ; 7.99\left(\mathrm{t}, 4 \mathrm{H},{ }^{3} J_{\mathrm{HH}}=7.2 \mathrm{~Hz}, 5,15-m 1-\mathrm{Ph}\right) ; 7.82\left(\mathrm{t}, 2 \mathrm{H},{ }^{3} J_{\mathrm{HH}}=7.2\right.$ $\mathrm{Hz}, 10-m 1-\mathrm{Ph}) ; 7.75\left(\mathrm{t}, 4 \mathrm{H},{ }^{3} J_{\mathrm{HH}}=7.2 \mathrm{~Hz}, 5,15-p-\mathrm{Ph}\right) ; 7.69$ (t, $\left.2 \mathrm{H},{ }^{3} J_{\mathrm{HH}}=7.2 \mathrm{~Hz}, 10-p-\mathrm{Ph}\right) ; 7.55$ $\left(\mathrm{t}, 4 \mathrm{H},{ }^{3} J_{\mathrm{HH}}=7.2 \mathrm{~Hz}, 5,15-m 2-\mathrm{Ph}\right) ; 7.45\left(\mathrm{t}, 2 \mathrm{H},{ }^{3} J_{\mathrm{HH}}=7.2 \mathrm{~Hz}, 10-m 2-\mathrm{Ph}\right) ; 7.33\left(\mathrm{~d}, 4 \mathrm{H},{ }^{3} J_{\mathrm{HH}}=\right.$ $8.2 \mathrm{~Hz}, 5,15-o 2-\mathrm{Ph}) ; 7.13$ (d, 2H, $\left.{ }^{3} J_{\mathrm{HH}}=7.2 \mathrm{~Hz}, 10-m 2-\mathrm{Ph}\right)$. HRMS (ESI): $\mathrm{M}^{+}=1250.2009$ (expt), 1250.1986 (calcd for $\mathrm{C}_{74} \mathrm{H}_{46} \mathrm{~N}_{8} \mathrm{Ru}_{2}$, major isotopomer). Elemental analysis (\%): found $\mathrm{C}$ 70.85, H 3.49, N 8.62; calcd C 71.14, H 3.71, N 8.97.

$\left\{\mathbf{R u}\left[\mathbf{T} \boldsymbol{p} \mathbf{C H}_{3} \mathbf{P C}\right]\right\}_{2}$. Yield $17.25 \mathrm{mg}(0.0129 \mathrm{mmol}, 19.0 \%)$. UV-vis $\left(\mathrm{CH}_{2} \mathrm{Cl}_{2}\right) \lambda_{\max }(\mathrm{nm})$ and $\varepsilon \times 10^{-4}\left(\mathrm{M}^{-1} \mathrm{~cm}^{-1}\right): 329$ (9.61), 398 (8.54), 538(2.29). ${ }^{1} \mathrm{H} \mathrm{NMR}\left(400 \mathrm{MHz},-20^{\circ} \mathrm{C}\right): \delta 8.83$ $\left(\mathrm{d}, 4 \mathrm{H},{ }^{3} J_{\mathrm{HH}}=8.44 \mathrm{~Hz}, 5,15-o 1-\mathrm{Ph}\right) ; 8.67$ (d, 2H, $\left.{ }^{3} J_{\mathrm{HH}}=7.48 \mathrm{~Hz}, 10-o 1-\mathrm{Ph}\right) ; 8.45$ (bs, $\left.4 \mathrm{H}, \beta-\mathrm{H}\right)$; $8.32(\mathrm{bs}, 4 \mathrm{H}, \beta-\mathrm{H}) ; 7.89\left(\mathrm{~d}, 4 \mathrm{H},{ }^{3} J_{\mathrm{HH}}=7.48 \mathrm{~Hz}, 5,15-m 1-\mathrm{Ph}\right) ; 7.80(\mathrm{bs}, 8 \mathrm{H}, \beta-\mathrm{H}) ; 7.71(\mathrm{~d}, 2 \mathrm{H}$, $\left.{ }^{3} J_{\mathrm{HH}}=7.48 \mathrm{~Hz}, 10-m 1-\mathrm{Ph}\right) ; 7.45\left(\mathrm{~d}, 4 \mathrm{H},{ }^{3} J_{\mathrm{HH}}=8.48 \mathrm{~Hz}, 5,15-o 2-\mathrm{Ph}\right) ; 7.34\left(\mathrm{~d}, 2 \mathrm{H},{ }^{3} J_{\mathrm{HH}}=8.44\right.$ $\mathrm{Hz}, 10-o 2-\mathrm{Ph}) ; 7.15\left(\mathrm{~d}, 4 \mathrm{H},{ }^{3} J_{\mathrm{HH}}=7.72 \mathrm{~Hz}, 5,15-m 2-\mathrm{Ph}\right) ; 6.93\left(\mathrm{~d}, 2 \mathrm{H},{ }^{3} J_{\mathrm{HH}}=8.44 \mathrm{~Hz}, 10-m 2-\right.$ $\mathrm{Ph}$ ); 2.82 (s, 12H, 5,15-p- $\left.\mathrm{CH}_{3}\right) ; 2.76$ (s, 6H, 10-p- $\mathrm{CH}_{3}$ ). HRMS (ESI): $\mathrm{M}^{+}=1334.2867$ (expt), 1334.2903 (calcd for $\mathrm{C}_{80} \mathrm{H}_{58} \mathrm{~N}_{8} \mathrm{Ru}_{2}$, major isotopomer). Elemental analysis (\%): found $\mathrm{C} 70.12$, H 4.98, N 7.84; calcd: C 72.05, H 4.38, N 8.40.

$\left\{\mathbf{R u}\left[\mathbf{T p} \mathbf{O C H} \mathbf{H}_{3} \mathbf{P C}\right]\right\}_{2}$. Yield $15.3 \mathrm{mg}(0.0106 \mathrm{mmol}, 15.7 \%)$. UV-vis $\left(\mathrm{CH}_{2} \mathrm{Cl}_{2}\right) \lambda_{\max }(\mathrm{nm})$ and $\varepsilon \times 10^{-4}\left(\mathrm{M}^{-1} \mathrm{~cm}^{-1}\right): 329$ (7.66), 406 (8.06), 533(2.85). ${ }^{1} \mathrm{H} \mathrm{NMR}\left(400 \mathrm{MHz},-20^{\circ} \mathrm{C}\right): \delta 8.88$ $\left(\mathrm{d}, 4 \mathrm{H},{ }^{3} J_{\mathrm{HH}}=8.08 \mathrm{~Hz}, 5,15-o 1-\mathrm{Ph}\right) ; 8.86\left(\mathrm{~d}, 2 \mathrm{H},{ }^{3} J_{\mathrm{HH}}=8.92 \mathrm{~Hz}, 10-o 1-\mathrm{Ph}\right) ; 8.69\left(\mathrm{~d}, 4 \mathrm{H},{ }^{3} J_{\mathrm{HH}}=\right.$ $3.88 \mathrm{~Hz}, \beta-\mathrm{H}) ; 8.58\left(\mathrm{~d}, 4 \mathrm{H},{ }^{3} J_{\mathrm{HH}}=3.88 \mathrm{~Hz}, \beta-\mathrm{H}\right) ; 8.22(\mathrm{bs}, 8 \mathrm{H}, \beta-\mathrm{H}) ; 7.52\left(\mathrm{~d}, 4 \mathrm{H},{ }^{3} J_{\mathrm{HH}}=8.08\right.$ $\mathrm{Hz}, 5,15-m 1-\mathrm{Ph}) ; 7.42\left(\mathrm{~d}, 2 \mathrm{H},{ }^{3} J_{\mathrm{HH}}=8.08 \mathrm{~Hz}, 10-m 1-\mathrm{Ph}\right) ; 7.26\left(\mathrm{~d}, 4 \mathrm{H},{ }^{3} J_{\mathrm{HH}}=8.08 \mathrm{~Hz}, 5,15-o 2-\right.$ $\mathrm{Ph}) ; 7.09\left(\mathrm{~d}, 4 \mathrm{H},{ }^{3} J_{\mathrm{HH}}=8.64 \mathrm{~Hz}, 5,15-m 2-\mathrm{Ph}\right) ; 7.07\left(\mathrm{~d}, 2 \mathrm{H},{ }^{3} J_{\mathrm{HH}}=8.04 \mathrm{~Hz}, 10-o 2-\mathrm{Ph}\right) ; 7.01(\mathrm{~d}$, $\left.2 \mathrm{H},{ }^{3} J_{\mathrm{HH}}=8.44 \mathrm{~Hz}, 10-m 2-\mathrm{Ph}\right) ; 4.10\left(\mathrm{~s}, 12 \mathrm{H}, 5,15-p-\mathrm{OCH}_{3}\right) ; 4.07$ (s, 6H, 10- $\left.-\mathrm{OCH}_{3}\right) . \mathrm{HRMS}$ (ESI): $\mathrm{M}^{+}=1430.2481$ (expt), 1430.2445 (calcd for $\mathrm{C}_{80} \mathrm{H}_{58} \mathrm{~N}_{8} \mathrm{O}_{6} \mathrm{Ru}_{2}$, major isotopomer). Elemental analysis (\%): found C 65.07, H 5.47, N 6.41; calcd C 67.22, H 4.09, N 7.84.

General procedure for the synthesis of $\{\mathbf{O s}[\mathbf{T p X P C}]\}_{2}$. A two-necked $50-\mathrm{mL}$ roundbottom flask was charged with free-base corrole, $\mathrm{H}_{3}[\mathrm{~T} p \mathrm{XPC}](0.109 \mathrm{mmol}), \mathrm{Os}_{3}(\mathrm{CO})_{12}(0.109$ mmol, $98.75 \mathrm{mg})$, potassium carbonate $(100 \mathrm{mg})$, 1,2,4-trichlorobenzene $(10 \mathrm{~mL})$, and a stirring bar. The contents were deoxygenated with a constant flow of argon for $10 \mathrm{~min}$ and then heated $\left(180^{\circ} \mathrm{C}\right)$ overnight with constant stirring under Ar. Completion of the reaction was indicated by the disappearance of the Soret absorption band of the free-base corrole and appearance of a new split Soret band with maxima at approximately 287 and $407 \mathrm{~nm}$. Upon cooling, the reaction mixture was loaded directly on to a silica gel column with $n$-hexane as the mobile phase. 1,2,4- 
Trichlorobenzene was first removed by eluting with pure hexane. $n$-Hexane/dichloromethane (1:3) mixtures were then used to elute the reddish-brown Os corrole dimer. Subsequent preparative thin-layer chromatography with 1:3 hexane/dichloromethane resulted in final yields of $35-46 \%$. Analytical details for the Os corrole dimers are given below.

$\left\{\right.$ Os[TpCF 3 PC]\} 2. Yield $35.0 \mathrm{mg}(0.019 \mathrm{mmol}, 35.0 \%)$. UV-vis $\left(\mathrm{CH}_{2} \mathrm{Cl}_{2}\right) \lambda_{\max }(\mathrm{nm})$ and $\varepsilon \times 10^{-4}\left(\mathrm{M}^{-1} \mathrm{~cm}^{-1}\right): 287$ (6.46), 363 (4.65), 407 (6.88), 583 (1.17). ${ }^{1} \mathrm{H}$ NMR (400 MHz, -20 $\left.{ }^{\circ} \mathrm{C}\right): \delta$ $9.05\left(\mathrm{~d}, 4 \mathrm{H},{ }^{3} J_{\mathrm{HH}}=7.88 \mathrm{~Hz}, 5,15-\mathrm{o} 1-\mathrm{Ph}\right) ; 9.00$ (d, 2H, $\left.{ }^{3} J_{\mathrm{HH}}=7.36 \mathrm{~Hz}, 10-o 1-\mathrm{Ph}\right) ; 8.88$ (bs, 4H, $\beta$-H); $8.69\left(\mathrm{~d}, 4 \mathrm{H},{ }^{3} J_{\mathrm{HH}}=5.08 \mathrm{~Hz}, \beta-\mathrm{H}\right) ; 8.45(\mathrm{bs}, 4 \mathrm{H}, \beta-\mathrm{H}) ; 8.40\left(\mathrm{~d}, 4 \mathrm{H},{ }^{3} J_{\mathrm{HH}}=4.32 \mathrm{~Hz}, \beta-\mathrm{H}\right)$; $8.25\left(\mathrm{~d}, 4 \mathrm{H},{ }^{3} J_{\mathrm{HH}}=7.36 \mathrm{~Hz}, 5,15-m 1-\mathrm{Ph}\right) ; 8.20\left(\mathrm{~d}, 2 \mathrm{H},{ }^{3} J_{\mathrm{HH}}=8.12 \mathrm{~Hz}, 10-m 1-\mathrm{Ph}\right) ; 7.87(\mathrm{~d}, 4 \mathrm{H}$, $\left.{ }^{3} J_{\mathrm{HH}}=7.88 \mathrm{~Hz}, 5,15-m 2-\mathrm{Ph}\right) ; 7.79\left(\mathrm{~d}, 2 \mathrm{H},{ }^{3} J_{\mathrm{HH}}=8.60 \mathrm{~Hz}, 10-m 2-\mathrm{Ph}\right) ; 7.51\left(\mathrm{~d}, 4 \mathrm{H},{ }^{3} J_{\mathrm{HH}}=7.36\right.$ $\mathrm{Hz}, 5,15-o 2-\mathrm{Ph}) ; 7.34$ (d, 2H, $\left.{ }^{3} J_{\mathrm{HH}}=8.12 \mathrm{~Hz}, 10-o 2-\mathrm{Ph}\right) ;{ }^{13} \mathrm{C} \mathrm{NMR}\left(100 \mathrm{MHz}, \mathrm{CD}_{2} \mathrm{Cl}_{2}\right): \delta 29.82$, $115.84,117.26,118.03,123.56,124.15,124.36,124.61,125.03,125.34,126.24,126.96,128.24$, $129.11,129.50,129.82,130.15,130.37,134.25,134.31,134.89,139.93,140.51,142.41,144.05$, 144.67; ${ }^{19} \mathrm{~F}$ NMR: $\delta-62.41$ (s, 18F,5,10, 15- $p-\mathrm{CF}_{3}$, Ph). HRMS (ESI): $\mathrm{M}^{+}=1836.2311$ (expt), 1836.2282 (calcd for $\mathrm{C}_{80} \mathrm{H}_{40} \mathrm{~F}_{18} \mathrm{~N}_{8} \mathrm{Os}_{2}$ ). Elemental analysis (\%): found C 51.99, H 2.72, N 5.34; calcd C 52.34, H 2.20, N 6.10.

\{Os[TPC]\}2. Yield $29.5 \mathrm{mg}(0.02 \mathrm{mmol}, 38.0 \%)$. UV-vis $\left(\mathrm{CH}_{2} \mathrm{Cl}_{2}\right) \lambda_{\max }(\mathrm{nm})$ and $\varepsilon \times 10^{-4}$ $\left(\mathrm{M}^{-1} \mathrm{~cm}^{-1}\right): 287$ (11.45), 363 (8.20), 405 (11.66), 584 (1.96). ${ }^{1} \mathrm{H}$ NMR (400 MHz, $\left.-20^{\circ} \mathrm{C}\right): \delta 9.00$ $\left(\mathrm{d}, 4 \mathrm{H},{ }^{3} J_{\mathrm{HH}}=7.52 \mathrm{~Hz}, 5,15-o 1-\mathrm{Ph}\right) ; 8.82\left(\mathrm{~d}, 2 \mathrm{H},{ }^{3} J_{\mathrm{HH}}=7.52 \mathrm{~Hz}, 10-o 1-\mathrm{Ph}\right) ; 8.65$ (bs, 4H, $\left.\beta-\mathrm{H}\right)$; $8.54(\mathrm{bs}, 4 \mathrm{H}, \beta-\mathrm{H}) ; 8.15(\mathrm{bs}, 8 \mathrm{H}, \beta-\mathrm{H}) ; 8.04\left(\mathrm{t}, 4 \mathrm{H},{ }^{3} J_{\mathrm{HH}}=7.52 \mathrm{~Hz}, 5,15-m 1-\mathrm{Ph}\right) ; 7.88$ (t, 2H, $\left.{ }^{3} J_{\mathrm{HH}}=7.52 \mathrm{~Hz}, 10-m 1-\mathrm{Ph}\right) ; 7.74\left(\mathrm{t}, 4 \mathrm{H},{ }^{3} J_{\mathrm{HH}}=6.76 \mathrm{~Hz}, 5,15-p-\mathrm{Ph}\right) ; 7.68\left(\mathrm{t}, 2 \mathrm{H},{ }^{3} J_{\mathrm{HH}}=7.52 \mathrm{~Hz}\right.$, $10-p-\mathrm{Ph}) ; 7.57\left(\mathrm{t}, 4 \mathrm{H},{ }^{3} J_{\mathrm{HH}}=7.48 \mathrm{~Hz}, 5,15-m 2-\mathrm{Ph}\right) ; 7.48$ (t, $\left.2 \mathrm{H},{ }^{3} J_{\mathrm{HH}}=7.52 \mathrm{~Hz}, 10-m 2-\mathrm{Ph}\right) ; 7.31$ $\left(\mathrm{d}, 4 \mathrm{H},{ }^{3} J_{\mathrm{HH}}=7.52 \mathrm{~Hz}, 5,15-\mathrm{o} 2-\mathrm{Ph}\right) ; 7.12\left(\mathrm{~d}, 2 \mathrm{H},{ }^{3} J_{\mathrm{HH}}=7.52 \mathrm{~Hz}, 10-\mathrm{o} 2-\mathrm{Ph}\right) ;{ }^{13} \mathrm{C}$ NMR $(100$ $\left.\mathrm{MHz}, \mathrm{CD}_{2} \mathrm{Cl}_{2}\right): \delta 115.75,124.16,125.15,126.57,127.03,127.18,127.43,127.51,127.55$, 134.82, 139.89, 141.06. HRMS (ESI): $\mathrm{M}^{+}=1428.3063$ (expt), 1430.3039 (calcd for $\mathrm{C}_{74} \mathrm{H}_{46} \mathrm{~N}_{8} \mathrm{Os}_{2}$ ). Elemental analysis (\%): found $\mathrm{C} 61.47, \mathrm{H} 3.90, \mathrm{~N} 7.13$; calcd C 62.25, H 3.25, N 7.85 .

$\left\{\mathbf{O s}\left[\mathbf{T p} \mathbf{C H}_{3} \mathbf{P C}\right]\right\}_{2}$. Yield $38.0 \mathrm{mg}(0.025 \mathrm{mmol}, 46.12 \%)$. UV-vis $\left(\mathrm{CH}_{2} \mathrm{Cl}_{2}\right) \lambda_{\max }(\mathrm{nm})$ and $\varepsilon \times 10^{-4}\left(\mathrm{M}^{-1} \mathrm{~cm}^{-1}\right): 287$ (6.80), 363 (5.24), 407 (7.41), 585 (1.52). ${ }^{1} \mathrm{H} \mathrm{NMR}\left(400 \mathrm{MHz},-20^{\circ} \mathrm{C}\right.$ ): $\delta 8.81\left(\mathrm{~d}, 4 \mathrm{H},{ }^{3} J_{\mathrm{HH}}=8.36 \mathrm{~Hz}, 5,15-o 1-\mathrm{Ph}\right) ; 8.62\left(\mathrm{~d}, 2 \mathrm{H},{ }^{3} J_{\mathrm{HH}}=8.36 \mathrm{~Hz}, 10-o 1-\mathrm{Ph}\right) ; 8.49$ (bs, $4 \mathrm{H}, \beta-\mathrm{H}) ; 8.41$ (bs, $4 \mathrm{H}, \beta-\mathrm{H}$ ); 7.91 (d, $\left.4 \mathrm{H},{ }^{3} J_{H H}=7.36 \mathrm{~Hz}, 5,15-m 1-\mathrm{Ph}\right) ; 7.85$ (bs, $\left.4 \mathrm{H}, \beta-\mathrm{H}\right)$; $7.75\left(\mathrm{~d}, 2 \mathrm{H},{ }^{3} J_{\mathrm{HH}}=8.32 \mathrm{~Hz}, 10-m 1-\mathrm{Ph}\right) ; 7.69(\mathrm{bs}, 4 \mathrm{H}, \beta-\mathrm{H}) ; 7.44\left(\mathrm{~d}, 4 \mathrm{H},{ }^{3} J_{\mathrm{HH}}=7.36 \mathrm{~Hz}, 5,15-\right.$ 
$m 2-\mathrm{Ph}) ; 7.35\left(\mathrm{~d}, 2 \mathrm{H},{ }^{3} J_{\mathrm{HH}}=8.36 \mathrm{~Hz}, 10-m 2-\mathrm{Ph}\right) ; 7.17\left(\mathrm{~d}, 4 \mathrm{H},{ }^{3} J_{\mathrm{HH}}=7.36 \mathrm{~Hz}, 5,15-o 2-\mathrm{Ph}\right) ; 6.96$ $\left(\mathrm{d}, 2 \mathrm{H},{ }^{3} J_{\mathrm{HH}}=8.36 \mathrm{~Hz}, 10-o 2-\mathrm{Ph}\right) ; 2.84\left(\mathrm{~s}, 12 \mathrm{H}, 5,15-p-\mathrm{CH}_{3}\right) ; 2.76\left(\mathrm{~s}, 6 \mathrm{H}, 10-p-\mathrm{CH}_{3}\right) ;{ }^{13} \mathrm{C} \mathrm{NMR}$ (100 MHz, $\left.\mathrm{CDCl}_{3}\right): \delta 19.74,20.99,22.25,23.50,114.88,116.58,119.46,122.83,123.84$, 124.57, 125.59, 125.98. 127.33, 127.66, 128.88, 133.35, 135.07, 136.79, 137.76, 138.34, 140.19, 141.14, 141.23, 142.08. HRMS (ESI): $\mathrm{M}^{+}=1512.4022$ (expt), 1514.3978 (calcd for $\mathrm{C}_{80} \mathrm{H}_{58} \mathrm{~N}_{8} \mathrm{Os}_{2}$ ). Elemental analysis (\%): found $\mathrm{C} 61.41, \mathrm{H} 4.53, \mathrm{~N}$ 6.63; calcd C 63.56, H 3.87, N 7.41 .

$\left\{\mathbf{O s}\left[\mathbf{T} p \mathbf{O C H} \mathbf{H}_{3} \mathbf{P C}\right]\right\}_{2}$. Yield $35.3 \mathrm{mg}(0.0219 \mathrm{mmol}, 40.31 \%)$. UV-vis $\left(\mathrm{CH}_{2} \mathrm{Cl}_{2}\right) \lambda_{\max }(\mathrm{nm})$ and $\varepsilon \times 10^{-4}\left(\mathrm{M}^{-1} \mathrm{~cm}^{-1}\right): 286$ (9.50), 365 (7.62), 407 (10.31), 585 (1.98). ${ }^{1} \mathrm{H}$ NMR (400 MHz, $\left.20^{\circ} \mathrm{C}\right): \delta 8.79\left(\mathrm{~d}, 4 \mathrm{H},{ }^{3} J_{\mathrm{HH}}=7.92 \mathrm{~Hz}, 5,15-o 1-\mathrm{Ph}\right) ; 8.65\left(\mathrm{~d}, 2 \mathrm{H},{ }^{3} J_{\mathrm{HH}}=7.60 \mathrm{~Hz}, 10-o 1-\mathrm{Ph}\right) ; 8.56$ (bs, $4 \mathrm{H}, \beta-\mathrm{H}) ; 8.46$ (bs, $4 \mathrm{H}, \beta-\mathrm{H}$ ); 7.88 (bs, $4 \mathrm{H}, \beta-\mathrm{H}) ; 7.67$ (bs, $4 \mathrm{H}, \beta-\mathrm{H}) ; 7.61\left(\mathrm{~d}, 4 \mathrm{H},{ }^{3} J_{\mathrm{HH}}=\right.$ $8.32 \mathrm{~Hz}, 5,15-m 1-\mathrm{Ph}$ ); $7.49\left(\mathrm{~d}, 2 \mathrm{H},{ }^{3} J_{\mathrm{HH}}=8.32 \mathrm{~Hz}, 10-m 1-\mathrm{Ph}\right.$ ); 7.16 (overlapping doublet, $4 \mathrm{H}$, ${ }^{3} J_{\mathrm{HH}}=7.8 \mathrm{~Hz}, 5,15-\mathrm{o} 2$ and $\left.m 2-\mathrm{Ph}\right) ; 7.07\left(\mathrm{~d}, 2 \mathrm{H},{ }^{3} J_{\mathrm{HH}}=8.32 \mathrm{~Hz}, 10-m 2-\mathrm{Ph}\right) ; 6.98\left(\mathrm{~d}, 2 \mathrm{H},{ }^{3} J_{\mathrm{HH}}=\right.$ $8.32 \mathrm{~Hz}, 10-o 2-\mathrm{Ph}$ ); 4.12 (s, 12H, 5,15-p-OCH $)$; 4.09 (s, 6H, 10-p-OCH $) ;{ }^{13} \mathrm{C}$ NMR (100 MHz, $\left.\mathrm{CDCl}_{3}\right): \delta 55.64,55.67,112.32,112.52,112.86,115.28,119.89,123.94,124.82,126.47,132.58$, $133.10,134.99,135.48,140.24,140.82,142.53,159.10,159.28$. HRMS (ESI): $\mathrm{M}^{+}=1608.3706$ (expt), 1610.3673 (calcd for $\mathrm{C}_{80} \mathrm{H}_{58} \mathrm{~N}_{8} \mathrm{O}_{6} \mathrm{Os}_{2}$, major isotopomer). Elemental analysis (\%): found C 59.11, H 4.10, N 6.57; calcd C 59.76, H 3.64, N 6.97.

Crystallization and crystallography. X-ray data were collected on beamline 11.3.1 at the Advanced Light Source of Lawrence Berkeley National Laboratory, Berkeley, California. The samples were mounted on MiTeGen ${ }^{\circledR}$ kapton loops and placed in a 100(2) K nitrogen cold stream provided by an Oxford Cryostream 700 Plus low temperature apparatus on the goniometer head of a Bruker D8 diffractometer equipped with an APEXII CCD detector. Diffraction data were collected using synchrotron radiation monochromated with silicon(111) to wavelengths of $0.7749(1), 0.7749(1)$, and $0.8856(1) \AA$ for $\left\{\mathrm{Os}\left[\mathrm{Tp} p \mathrm{CF}_{3} \mathrm{C}\right]\right\}_{2},\{\mathrm{Os}[\mathrm{TPC}]\}_{2}$ and $\{\mathrm{Os}[\mathrm{TpOMeC}]\}_{2}$, respectively. In each case, an approximate full-sphere of data was collected using $1^{\circ} \omega$ scans. Absorption corrections were applied with SADABS..$^{54}$ The structures were solved by intrinsic phasing methods (SHELXT) ${ }^{55}$ and refined by full-matrix least squares on $F^{2}$ (SHELXL-2018). ${ }^{56}$ Appropriate scattering factors were applied using the $\mathrm{XDISP}^{57}$ program within the WinGX suite. ${ }^{58}$ Hydrogen atoms were geometrically calculated and refined as riding atoms. 
All three compounds displayed some disorder of the corrole substituents, which were modeled with occupancies that were restrained to sum to 1.00. Equivalent atoms were constrained to have equal $\mathrm{U}_{\mathrm{ij}}$ values. For $\{\mathrm{Os}[\mathrm{T} p \mathrm{OMeC}]\}_{2}$ and $\{\mathrm{Os}[\mathrm{TPC}]\}_{2}$, the partial occupancy atoms were refined with isotropic thermal displacement parameters. In all cases, equivalent partial occupancy atoms were restrained to have equal $\mathrm{U}_{\mathrm{ij}}$ values and equivalent disordered groups were restrained to have equal bond lengths and angles.

Large residual peaks of electron density $\left(\sim 2.5 \mathrm{e} / \AA^{3}\right)$ were observed for both $\left\{\mathrm{Os}\left[\mathrm{T} p \mathrm{CF}_{3} \mathrm{C}\right]\right\}_{2}$ and $\{\mathrm{Os}[\mathrm{TpOMeC}]\}_{2}$. As these were separated from either an Os center $\left(\{\mathrm{Os}[\mathrm{T} p \mathrm{OMeC}]\}_{2}\right)$ or a second large peak of electron density $\left(\left\{\mathrm{Os}\left[\mathrm{T}_{p} \mathrm{CF}_{3} \mathrm{C}\right]\right\}_{2}\right)$ by approximately 2.22 to $2.26 \AA$, they were presumed to correspond to either the Os centers in an extremely minor twin component or to extremely minor disorder.

A region of negative electron density $\left(\mathrm{ca}-6.5 \mathrm{e} / \AA^{3}\right)$ near Os 2 in $\{\mathrm{Os}[\mathrm{TPC}]\}_{2}$ suggested that the Os 2 center has less than $100 \%$ occupancy. The occupancy of Os 2 was allowed to freely refine, and refined to a value of approximately $71 \%$. This situation was observed for two different crystals of $\{\mathrm{Os}[\mathrm{TPC}]\}_{2}$. A residual peak of electron density near the Os2 centre, when modeled as a partial occupancy Os atom (Os3), refined to an occupancy of 2-4\%. Modeling this peak as an alternate Os site, however, reduced the occupancy of Os2 by a similar amount. As the relative occupancy of this Os 3 center is so low, we could not definitively determine whether it is an alternate location of the Os2 centre; this peak has accordingly been left unassigned in the final model. No attempt was made to reduce the occupancy of the atoms that make up the corrole unit.

Computational methods. All DFT calculations were carried out with the ADF 2016 program system. ${ }^{59}$ Relativistic effects were taken into account with the zeroth-order regular approximation (ZORA) applied as a scalar correction and specially optimized all-electron ZORA STO-TZP basis sets for such calculations. A parallel set of calculations were carried out with the same basis set but with a nonrelativistic Hamiltonian. A variety of exchange-correlation functionals were tested; however, since the results proved largely consistent, the discussion above only refers to the B3LYP-D3 results. 


\section{Acknowledgement}

This work was supported by project 262229 of the Research Council of Norway (AG). This research used resources of the Advanced Light Source, which is a DOE Office of Science User Facility under contract no. DE-AC02-05CH11231.

\section{ASSOCCIATED CONTENT}

Supporting Information Available. ${ }^{1} \mathrm{H},{ }^{19} \mathrm{~F}$ and ${ }^{13} \mathrm{C}$ NMR spectra; HR-ESI mass spectra; selected molecular orbitals; optimized Cartesian coordinates (32 pages). 


\section{References}

( ${ }^{1}$ Cotton, F. A.; Wilkinson, G.; Murillo, C. A.; Bochmann, M. Advanced Inorganic Chemistry, $6^{\text {th }}$ ed. Wiley: New York, 1999, pp. 758-775.

$\left({ }^{2}\right)$ Pyykkö, P. Relativistic Effects in Chemistry: More Common Than You Thought. Annu. Rev. Phys. Chem. 2012, 63, 45-64.

$\left(^{3}\right)$ Autschbach, J. Perspective: Relativistic effects. J. Chem. Phys. 2012, 136, 150902.

$\left({ }^{4}\right)$ Gorin, D. J.; Toste, F. D. Relativistic effects in homogeneous gold catalysis. Nature 2007, 446, 395-403.

$\left(^{5}\right)$ Vicha, J.; Novotny, J.; Straka, M.; Repisky, M.; Ruud, K.; Komorovsky, S.; Marek, R.

Structure, solvent, and relativistic effects on the NMR chemical shifts in square-planar transitionmetal complexes: assessment of DFT approaches. Phys. Chem. Chem. Phys. 2015, 17, 2494424955.

$\left({ }^{6}\right)$ Jerabek, P.; Esch, B. v. d.; Schmidbaur, H.; Schwerdtfeger, P. Influence of Relativistic Effects on Bonding Modes in $\mathrm{M}(\mathrm{II})$ Dinuclear Complexes $(\mathrm{M}=\mathrm{Au}, \mathrm{Ag}$, and $\mathrm{Cu})$. Inorg. Chem. 2017, $56,14624-14631$.

( $\left.{ }^{7}\right)$ Alvarez-Thon, L.; David, J.; Arratia-Pérez, R.; Seppelt, K. Ground state of octahedral platinum hexafluoride. Phys. Rev. A. 2008, 77, 034502.

$\left({ }^{8}\right)$ Conradie, J.; Ghosh, A. The Blue-Violet Color of Pentamethylbismuth: A Visible Spin-Orbit Effect. ChemistryOpen 2017, 6, 15-17.

$\left({ }^{9}\right)$ Ghosh, A.; Conradie, J. The Valence States of Copernicium and Flerovium. Eur. J. Inorg. Chem. 2016, 2989-2992.

$\left({ }^{10}\right)$ Demissie, T. B.; Garabato, B. D.; Ruud, K.; Kozlowski, P. M. Mercury Methylation by Cobalt Corrinoids: Relativistic Effects Dictate the Reaction Mechanism. Angew. Chem. Int. Ed. 2016, 55, 11503-11506.

( ${ }^{11}$ ) Demissie, T. B.; Conradie, J.; Vazquez-Lima, H.; Ruud, K.; Ghosh, A. Rare and Nonexistent Nitrosyls: Periodic Trends and Relativistic Effects in Ruthenium and Osmium Porphyrin-Based $\{\mathrm{MNO}\}^{7}$ Complexes. ACS Omega 2018, 3, 10513-10516.

$\left({ }^{12}\right)$ Jérôme, F.; Billier, B.; Barbe, J.-M.; Espinosa, E.; Dahaoui, S.; Lecomte, C.; Guilard, R. Evidence for the Formation of $\mathrm{a} \mathrm{Ru}^{\mathrm{III}}-\mathrm{Ru}^{\mathrm{III}}$ Bond in a Ruthenium Corrole Homodimer. Angew. Chem. Int. Ed. 2000, 39, 4051-4053. 
$\left({ }^{13}\right)$ Kadish, K. M.; Burdet, F.; Jerome, F.; Barbe, J.-M.; Ou, Z.; Shao, J.; Guilard, R. Synthesis, Physicochemical and Electrochemical Properties of Metal-Metal Bonded Ruthenium Corrole Homodimers. J. Organomet. Chem. 2002, 652, 69-76.

$\left({ }^{14}\right)$ Simkhovich, L.; Luobeznova, I.; Goldberg, I.; Gross, Z. Mono- and Binuclear Ruthenium Corroles: Synthesis, Spectroscopy, Electrochemistry, and Structural Characterization. Chem. Eur. J. 2003, 9, 201-208.

$\left({ }^{15}\right)$ Alemayehu, A. B.; Vazquez-Lima, H. Gagnon, K. J.; Ghosh, A. Stepwise Deoxygenation of Nitrite as a Route to Two Families of Ruthenium Corroles: Group 8 Periodic Trends and Relativistic Effects. Inorg. Chem. 2017, 56, 5285-5294.

$\left({ }^{16}\right)$ Alemayehu, A. B.; Gagnon, K. J.; Terner, J.; Ghosh, A. Oxidative Metalation as a Route to Size-Mismatched Macrocyclic Complexes: Osmium Corroles. Angew. Chem. Int. Ed. 2014, 53, 14411-14414.

$\left({ }^{17}\right)$ Palmer, J. H.; Durrell, A. C.; Gross, Z.; Winkler, J. R.; Gray, H. B. Near-IR Phosphorescence of Iridium(III) Corroles at Ambient Temperature. J. Am. Chem. Soc. 2010, 132, 9230-9231.

$\left({ }^{18}\right)$ Sinha, W.; Ravotto, L.; Ceroni, P.; Kar, S. NIR-Emissive Iridium(III) Corrole Complexes as Efficient Singlet Oxygen Sensitizers. Dalton Trans. 2015, 44, 17767-73.

$\left({ }^{19}\right)$ Alemayehu, A. B.; Jae Day, N. U.; Mani, T.; Rudine, A. B.; Thomas, K. E.; Gederaas, O. A.; Vinogradov, S. A.; Wamser, C. C.; Ghosh, A. Gold Tris(carboxyphenyl)corroles as Multifunctional Materials: Room Temperature Near-IR Phosphorescence and Applications to Photodynamic Therapy and Dye-Sensitized Solar Cells. ACS Appl. Mater. Interfaces 2016, 8, 18935-18942.

$\left({ }^{20}\right)$ Lemon, C. M.; Powers, D. C.; Brothers, P. J.; Nocera, D. G. Gold Corroles as Near-IR Phosphors for Oxygen Sensing. Inorg. Chem. 2017, 56, 10991-10997.

$\left({ }^{21}\right)$ Alemayehu, A. B.; McCormick, L. J.; Gagnon, K. J.; Borisov, S. M.; Ghosh, A. Stable Platinum(IV) Corroles: Synthesis, Molecular Structure, and Room-Temperature Near-IR Phosphorescence. ACS Omega 2018, 3, 9360-9368.

$\left({ }^{22}\right)$ Borisov, S. M.; Alemayehu, A.; Ghosh, A. Osmium-Nitrido Corroles as NIR Indicators for Oxygen Sensors and Triplet Sensitizers for Organic Upconversion and Singlet Oxygen Generation. J. Mater. Chem. C 2016, 4, 5822-5828.

$\left({ }^{23}\right)$ Cotton, F. A. Metal-Metal Bonding in $\left[\mathrm{Re}_{2} \mathrm{X}_{8}\right]^{2-}$ Ions and Other Metal Atom Clusters. Inorg. Chem. 1965, 4, 334-336. 
$\left.{ }^{(24}\right)$ Collman, J. P.; Barnes, C. E.; Woo, L. K. Systematic variation of metal-metal bond order in metalloporphyrin dimers. 1983, 80, 7684-7688.

$\left({ }^{25}\right)$ Collman, J. P.; Barnes, C. E.; Swepston, P. N.; Ibers, J. A. Synthesis, proton NMR, and structural characterization of binuclear ruthenium porphyrin dimers. J. Am. Chem. Soc. 1984, 106, 3500-3510.

$\left({ }^{26}\right)$ Collman, J. P.; Arnold, H. J. Multiple Metal-Metal Bonds in 4d and 5d Metal-Porphyrin Dimers. Acc. Chem. Res. 1993, 26, 586-592.

$\left({ }^{27}\right)$ The broadness of the $\beta$-H signals for certain compounds suggests a degenerate dynamic process, most likely involving rotation about the Os-Os bond; in general, these signals sharpened at lower temperatures. Importantly, in each case, we could discern only four distinct $\beta$-H signals, confirming the preponderance of a single dimer conformation with symmetry-related corrole units.

$\left({ }^{28}\right)$ Becke, A. D. Density-functional exchange-energy approximation with correct asymptotic behavior. Phys. Rev. A 1988, 38, 3098-3100.

$\left({ }^{29}\right)$ Lee, C.; Yang, W.; Parr, R. G. Development of the Colle-Salvetti correlation-energy formula into a functional of the electron density. Phys. Rev. B 1988, 37, 785-789.

$\left.{ }^{(30}\right)$ Stephens, J.; Devlin, F. J.; Chabalowski, C. F.; Frisch, M. J. Ab Initio Calculation of Vibrational Absorption and Circular Dichroism Spectra Using Density Functional Force Fields. J. Phys. Chem. 1994, 98, 11623-11627.

$\left.{ }^{31}\right)$ Grimme, S.; Anthony, J.; Ehrlich, S.; Krieg, H. A Consistent and Accurate Ab Initio Parametrization of Density Functional Dispersion Correction (DFT-D) for the 94 Elements H-Pu J. Phys. Chem. 2010, 132, Art. no. 154104.

${ }^{32}$ van Lenthe, E.; Baerends, E. J.; Snijders, J. G. Relativistic regular two-component Hamiltonians. J. Chem. Phys. 1993, 99, 4597-4610.

${ }^{33}$ van Lenthe, E.; Baerends, E. J.; Snijders, J. G. Relativistic total energy using regular approximations. J. Chem. Phys. 1994, 101, 9783-9792.

$\left.{ }^{(34}\right)$ Ziegler, T. Theoretical study of the triple metal bond in $\mathrm{d}^{3}-\mathrm{d}^{3}$ binuclear complexes of chromium, molybdenum, tungsten by the Hartree-Fock-Slater transition state method. J. Am. Chem. Soc. 1983, 105, 7543-7549. 
$\left.{ }^{35}\right)$ Ziegler, T. Theoretical study of multiple metal-metal bonds in binuclear complexes of Group $6 \mathrm{~d}$ and Group $7 \mathrm{~d}$ transition elements with the general formula $\mathrm{M}_{2} \mathrm{Cl}_{4}\left(\mathrm{PH}_{3}\right)_{4}{ }^{\mathrm{n}+}(\mathrm{n}=0,1,2)$ by the Hartree-Fock-Slater transition-state method. J. Am. Chem. Soc. 1984, 106, 5901-5908.

$\left.{ }^{36}\right)$ Ziegler, T. Theoretical study on the quadruple metal bond in $\mathrm{d}^{4}-\mathrm{d}^{4}$ binuclear tetracarboxylate complexes of chromium, molybdenum, and tungsten by the Hartree-Fock-Slater transition-state method. J. Am. Chem. Soc. 1985, 107, 4453-4459.

$\left.{ }^{37}\right)$ Ponec, R.; Bučinský, L.; Gatti, Relativistic Effects on Metal-Metal Bonding: Comparison of the Performance of ECP and Scalar DKH Description on the Picture of Metal-Metal Bonding in $\mathrm{Re}_{2} \mathrm{Cl}_{8}{ }^{2-}$. J. Chem. Theory Comput. 2010, 6, 3113-3121.

$\left.{ }^{38}\right)$ Alemayehu, A. B.; Vazquez-Lima, H.; Gagnon, K. J.; Ghosh, A. Tungsten Biscorroles: New Chiral Sandwich Compounds. Chem. Eur. J. 2016, 22, 6914-6920.

$\left.{ }^{39}\right)$ Alemayehu, A.; Vazquez-Lima, H.; McCormick, L. J.; Ghosh, A. Relativistic effects in metallocorroles: comparison of molybdenum and tungsten biscorroles. Chem. Commun. 2017, 53, 5830-5833.

$\left({ }^{40}\right)$ Schies, C.; Alemayehu, A. B.; Vazquez-Lima, H.; Thomas, K. E.; Bruhn, T.; Bringmann, G.; Ghosh, A. Metallocorroles as inherently chiral chromophores: resolution and electronic circular dichroism spectroscopy of a tungsten biscorrole. Chem. Commun. 2017, 53, 6121-6124.

$\left({ }^{41}\right)$ Ghosh, A. Electronic Structure of Corrole Derivatives: Insights from Molecular Structures, Spectroscopy, Electrochemistry, and Quantum Chemical Calculations. Chem. Rev. 2017, 117, 3798-3881.

$\left.{ }^{(42}\right)$ Johansen, I.; Norheim, H.-K.; Larsen, S.; Alemayehu, A. B.; Conradie, J.; Ghosh, A.

Substituent Effects on Metallocorrole Spectra: Insights from Chromium-Oxo and MolybdenumOxo Triarylcorroles. J. Porphyrins Phthalocyanines 2011, 15, 1335-1344.

$\left({ }^{43}\right)$ Alemayehu, A. B.; Vazquez-Lima, H. Gagnon, K. J.; Ghosh, A. Stepwise Deoxygenation of Nitrite as a Route to Two Families of Ruthenium Corroles: Group 8 Periodic Trends and Relativistic Effects. Inorg. Chem. 2017, 56, 5285-5294.

$\left({ }^{44}\right)$ Einrem, R. F.; Gagnon, K. J.; Alemayehu, A. B.; Ghosh, A. Metal-Ligand Misfits: Facile Access to Rhenium-Oxo Corroles by Oxidative Metalation. Chem. Eur. J. 2016, 22, 517-520.

$\left({ }^{45}\right)$ Alemayehu, A. B.; Vazquez-Lima, H.; Beavers, C. M.; Gagnon, K. J.; Bendix, J.; Ghosh, A. Platinum Corroles. Chem. Comm. 2014, 50, 11093-11096. 
$\left({ }^{46}\right)$ Alemayehu, A B.; Ghosh, A. Gold Corroles. J. Porphyrins Phthalocyanines 2011, 15, 106110.

$\left({ }^{47}\right)$ Rabinovitch, E.; Goldberg, I.; Gross, Z. Gold(I) and Gold(III) Corroles. Chem. Eur. J. 2011, 17, 12294-12301.

$\left({ }^{48}\right)$ Thomas, K. E.; Alemayehu, A. B.; Conradie, J.; Beavers, C.; Ghosh, A. Synthesis and Molecular Structure of Gold Triarylcorroles. Inorg. Chem. 2011, 50, 12844-12851.

$\left({ }^{49}\right)$ Thomas, K. E.; Vazquez-Lima, H.; Fang, Y.; Song, Y.; Gagnon, K. J.; Beavers, C. M.; Kadish, K. M.; Ghosh, A. Ligand Noninnocence in Coinage Metal Corroles: A Silver KnifeEdge. Chem. Eur. J. 2015, 21, 16839-16847.

$\left.{ }^{(50}\right)$ Gouterman, M.; Wagniére, G. H.; Snyder, L. C. Spectra of Porphyrins. Part II. Four-Orbital Model. J. Mol. Spectrosc. 1963, 11, 108-115.

${ }^{(51)}$ Gouterman, M. Optical Spectra and Electronic Structure of Porphyrins and Related Rings. In The Porphyrins; Dolphin, D., Ed.; Academic Press: New York, 1978; Vol. III, Part A, pp 1-165. $\left({ }^{52}\right)$ Koszarna, B.; Gryko, D. T. Efficient Synthesis of meso-Substituted Corroles in a $\mathrm{H}_{2} \mathrm{O}-\mathrm{MeOH}$ Mixture. J. Org. Chem. 2006, 71, 3707-3717.

$\left({ }^{53}\right)$ Many metalloporphyrins and metallocorroles, in particular hemes and Mn and Fe corroles do not yield satisfactory elemental analyses. Others, such as coinage metal corroles, do so readily. The present complexes turned out to be intermediate. Although the majority of analyses proved to be within $0.5 \%$ of their theoretical values, a few exhibited errors of $1-2 \%$. Although the latter can be accounted for by assuming tightly held solvent molecules, the theoretical analyses quoted here refer to simply the solvent-free molecular formulas.

$\left({ }^{54}\right)$ Krause, L.; Herbst-Irmer, R.; Sheldrick, G. M.; Stalke, D. Comparison of silver and molybdenum microfocus X-ray sources for single-crystal structure determination. J. Appl. Cryst. 2015, 48, 3-10.

${ }^{(55)}$ Sheldrick, G. M. SHELXT - Integrated Space-Group and Crystal-Structure Determination. Acta Cryst., 2015, A71, 3-8

$\left({ }^{56}\right)$ Sheldrick, G. M. Crystal Structure Refinement with SHELXL. Acta Cryst., 2015, C71, 3-8

${ }^{(57)}$ Kissel, L.; Pratt, R. H. Corrections to tabulated anomalous-scattering factors. Acta Cryst. 1990, $A 46,170-175$.

$\left({ }^{58}\right)$ Farrugia, L. J. WinGX and ORTEP for Windows: an update. $J$ Appl. Cryst. 2012, 45, 849854. 
$\left({ }^{59}\right)$ Velde, G. T.; Bickelhaupt, F. M.; Baerends, E. J.; Guerra, C. F.; van Gisbergen, S. J. A.; Snijders, J. G.; Ziegler, T. J. Comput. Chem. 2001, 22, 931-967. 